\title{
Density and shrinkage as guiding criteria for the optimization of the thermal conductivity of poly(urethane)-class aerogels
}

\author{
Sylwia Członka ${ }^{1}$ Massimo F. Bertino ${ }^{2} \cdot$ Jan Kośny $^{3} \cdot$ Nitin Shukla $^{3}$
}

Received: 18 August 2019 / Accepted: 4 October 2019 / Published online: 26 October 2019

(C) The Author(s) 2019

\begin{abstract}
We investigated the effect of gelation solvent, monomer type, and monomer concentration on the physical properties of freeze-dried poly(urethane)-poly(isocyanurate) (PUR-PIR) aerogels, with particular emphasis on their thermal conductivity. It was found that the gelation solvent considerably affects aerogel morphology and physical properties. Aerogels with the lowest thermal conductivity were obtained using a mixture of tetrahydrofuran (THF) and acetonitrile, in a 50\% volume ratio. The influence on thermal conductivity of polyol and isocyanate structure and of their concentration was also investigated. Rigid precursors, phloroglucinol (POL), and an aromatic polyisocyanate based on toluene diisocyanate (Desmodur RC) yielded the lowest thermal conductivity. Our results were compared with recent work reporting on parameters that could be used as predictors of thermal conductivity and other physical properties of organic aerogels. None of these parameters were found to be satisfactory predictors of aerogel properties. For example, no systematic correlation between solvent solubility parameters and aerogel properties was observed. We also examined the role of the K-index. This index, defined as the ratio between porosity and contact angle, was shown recently to be a good predictor of the properties of polyurea aerogels. While the thermal conductivity scaled with the K-index, the scaling was different for each of the isocyanate monomers considered in our experiments. Thermal conductivity, instead, scaled well with the product of density and shrinkage of aerogels, independent of monomer type. The reasons of this dependence on shrinkage and density are discussed, and the use of these parameters to guide experimentation on other systems is discussed. Physical properties such as static and dynamic compression modulus and thermal stability of the most promising formulations were also examined.
\end{abstract}

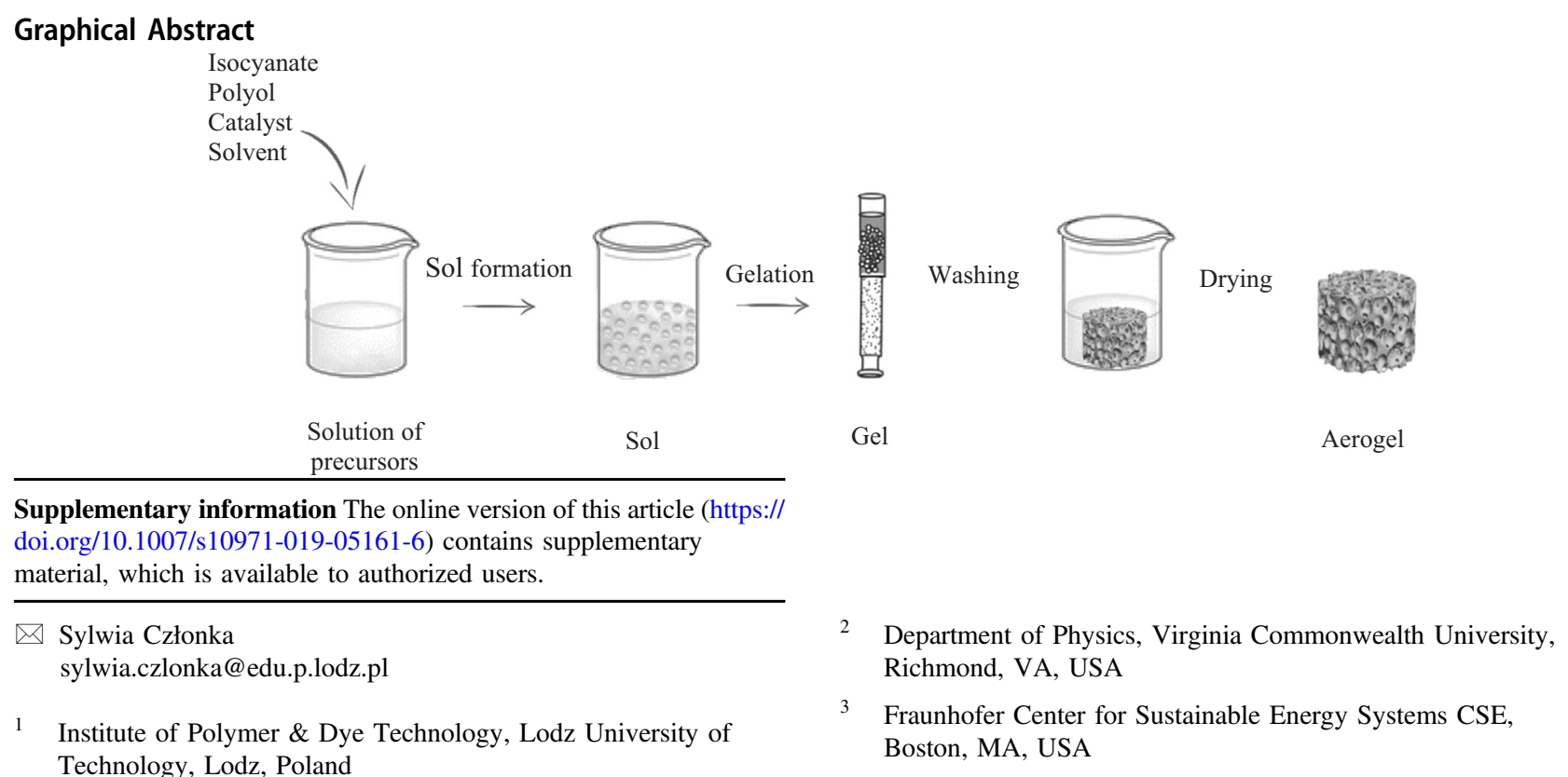


Keywords Polyurethane $\cdot$ Porous materials $\cdot$ Surface area $\cdot$ Thermal conductivity $\cdot$ Hansen solubility parameters

\section{Introduction}

Aerogels are materials characterized by low density, large surface area, and extremely low thermal conductivity. For a very long time, aerogels were limited to silica, which is still the most-investigated and best-known aerogel class. Starting from the 1990s, work appeared that focused on organic aerogels. Organic aerogels have a thermal conductivity comparable with that of silica aerogels, yet they are mechanically stronger [1]. Therefore, organic aerogels are among the most promising materials for the next generation of thermal superinsulators. Limiting our discussion to polyurethane-class aerogels (the focus of this work), we note that they were first documented in a patent filed by ICI in 1996 [2]. These polyurethane aerogels had a thermal conductivity of $0.020 \mathrm{~W} / \mathrm{mK}$ at atmospheric pressure. Beismans et al. [3, 4] synthesized polyurethane-based aerogels using solutions of aromatic isocyanates in dichloromethane. Aerogels with a bulk density of $0.15 \mathrm{~g} /$ $\mathrm{cm}^{3}$ and thermal conductivity of $0.022 \mathrm{~W} / \mathrm{mK}$ were obtained. Pirard et al. [5] produced polyurethane gel networks by reacting polyisocyanates with polyols. The resulting aerogels had a narrow pore size distribution and a density between 0.11 and $0.37 \mathrm{~g} / \mathrm{cm}^{3}$. Rigacci et al. [6] obtained polyurethane aerogels with density values in the range $0.12-0.22 \mathrm{~g} / \mathrm{cm}^{3}$ and thermal conductivity of $0.022 \mathrm{~W} / \mathrm{mK}$ by reacting 4,4-methylenebis(phenyl isocyanate) (MDI) with multifunctional polyols. Chidambareswarapattar et al. [7] synthesized an array of polyurethane aerogels with a density as low as $0.094 \mathrm{~g} / \mathrm{cm}^{3}$ and a surface area ranging from 0.5 to $241 \mathrm{~m}^{2} / \mathrm{g}$ using trifunctional isocyanates and multifunctional aromatic polyols. Zhu et al. [8] produced polyisocyanurate-polyurethane aerogels using commercial, two-component precursor systems. Depending on the solvent blend, aerogels with density in the range $0.15-0.53 \mathrm{~g} / \mathrm{cm}^{3}$ and thermal conductivity between 0.019 and $0.037 \mathrm{~W} / \mathrm{mK}$ were synthesized.

Different from silica aerogels, the properties of organic aerogels depend strongly on the synthesis conditions. Small variations of monomer concentration, temperature, monomer type, solvent polarity, and structure can lead to strong differences in density, morphology, porosity, and surface area, all factors which affect thermal conductivity. For example, the groups of Leventis and Reichenauer reported on polyurea aerogels and showed that changing the monomer concentration from 0.1 to $0.5 \mathrm{M}$ changed the skeletal morphology from wire-like to sphere-like [9]. The strong dependence of morphology and other physical properties on processing conditions represents an obstacle towards the development of organic aerogels. To understand the origin of the variability of organic aerogel synthesis it is best to start discussing the bulk polymerization process. Bulk urethane polymerization has been studied for a long time [10-12]. The reaction is quite complex and some of its details have yet to be clarified. In absence of catalysts, the reaction needs to be carried out at temperatures on the order of $60-80^{\circ} \mathrm{C}$ [11]. Early studies established that the solvent can affect the reaction rate by forming complexes with the reagents. For example, solvents, such as dimethylsulfoxide (DMSO) or dimethylformamide (DMF), which can form a hydrogen bond with the polyol, reduce the reaction rate by 3-5 times compared with benzene [13-15]. Base- and acidcatalyzed polymerization has also been investigated, and it was found that the reaction rate is higher for acid- than for base-catalyzed polymerization. For example, Ni et al. [16] found that the reaction rate was $K=1.19 \times 10^{-4}[\mathrm{~L} / \mathrm{mol} \mathrm{min}]$ for acid-catalyzed, and $K=6.01 \times 10^{-4}[\mathrm{~L} / \mathrm{mol} \mathrm{min}]$ for base-catalyzed polymerization of an aliphatic isocyanate (dicyclohexylmethane diisocyanate, HDI) and water. For acid catalysis, the most popular route involves organometallic compounds of $\mathrm{Sn}$, such as dibutyltin dilaurate (DBTDL) [10]. The organometallic compounds form complexes with the polyol and, possibly, with the isocyanates. These complexes are often short-lived and appear to depend on the type of precursors [17-21]. Solvents also affect the reaction rate of acid-catalyzed polymerization. However, to date, no evident correlation has been found between the solvent and reaction rate. For example, Kothandaraman and Nasar [19] reported that the reaction rate was benzene toluene $>$ chlorobenzene $>$ dioxane $>$ nitrobenzene. However, no clear dependence between reaction rate and solvent parameters such as hydrogen bonding index, dielectric constant or donor number could be identified.

The uncertainties of bulk polymerization are magnified when it comes to aerogels. The physical properties of aerogels depend strongly on density, skeletal morphology, nanoparticle connectivity, and porosity. To minimize thermal conductivity (the goal of this work), the materials must fulfill a series of requirements. The density must be low to minimize conductivity through the solid phase, but not too low, otherwise large pores are created where convection is allowed. Similarly, high porosity is necessary, but the pores must be small to inhibit convection. Skeletal morphology is also relevant. For example, fiber-like nanoparticles are not desirable, since they lower the percolation threshold of the solid phase [9]. These requirements on density, porosity, and morphology impose additional constraints on an already complex polymerization reaction. Recognizing the 
complexity of the problem, recent work by the groups of Rigacci, Koebel, Chidambareswarapattar, and Leventis has attempted to provide guiding criteria for the synthesis of polyurethane and polyurea aerogels $[6-8,22]$. The authors focused on the relationship between gelation solvent and aerogel properties. Their work showed that thermal conductivity was minimized when the polymer was soluble in the gelation solvent. Rigacci's group showed that the optimal solvent needed to have a Hildebrand parameter compatible with the polyurethane [6]. Koebel's group expanded on Rigacci's work and showed that a better predictor was the Hansen solubility parameter [8]. The Leventis group carried out a monumental work where about 200 polyurea aerogel formulations were analyzed [23]. This work found that the nature of the solvent has a dramatic effect on the sol-gel process, e.g., gelation versus precipitation, and aerogel properties, which in turn affect density, modulus and thermal conductivity. However, no clear-cut correlation between the Hansen solubility parameters and aerogel properties was observed. The authors introduced a new parameter, the $\mathrm{K}$-index, defined as the ratio between porosity and contact angle. The K-index was successfully used as a predictor of mechanical and thermal properties of polyurea aerogels. Leventis' work is remarkable and very thorough. However, the K-index cannot be calculated a priori for a generic system. The K-index can be calculated using a polynomial formula, but some of its coefficients depend on the monomer, preventing calculation of the Kindex without prior experimentation.

In this study, we show that the criteria suggested by other authors are not satisfactory predictors of morphology and physical properties of poly(urethane)-poly(isocyanurate) (PIR-PUR) aerogels. The work is not meant to comment negatively on the work of other groups. It shows, disappointingly, that organic aerogels are extremely complex and that it is difficult to anticipate the outcome of a synthesis. On the positive side, we show that thermal conductivity scales well with the product of density and shrinkage. This dependency makes sense for two reasons. The first reason is that thermal conductivity through the solid phase is very relevant in organic aerogels. For example, Leventis et al. [9] investigated the correlation between the microstructure, density and thermal conductivity of polyurea aerogels. The authors showed that the solid thermal conductivity of the polyurea aerogels increases linearly with density. Hence, the dependence on density observed in our work is not surprising. As for shrinkage, it is known that organic aerogels shrink considerably (up to $50 \%$ ) upon drying [9]. Shrinkage is due to the formation of hydrogen bonds between polymer strands. We have observed that in aerogels with high shrinkage $(>40 \%)$, polymer nanoparticles coalesced into ribbon-like aggregates. Necks between nanoparticles were broadened or disappeared altogether, and with that, one of the main bottlenecks to thermal energy transfer was removed.

Given the extreme sensitivity of organic aerogels to processing conditions, our findings may or may not be extended to other systems. We note, however, that measurements of density and shrinkage are extremely simple, and therefore the criteria found in our work may be used to guide rapid minimization of the thermal conductivity of other organic aerogels.

\section{Experimental}

\subsection{Chemicals}

Desmodur N3300A, Desmodur ILBA, and Desmodur RC triisocyanate were supplied from Covestro LLC. Desmodur $\mathrm{N} 3300 \mathrm{~A}$ is an aliphatic isocyanate resin based on hexamethylene diisocyanate (HDI). Desmodur ILBA is a polyisocyanate based on isophorone diisocyanate (IPDI), while Desmodur $\mathrm{RC}$ is an aromatic polyisocyanate based on toluene diisocyanate (TDI). Phloroglucinol (POL), 1,1,1-tris (hydroxyphenyl)ethane (HPE), resorcinol (RES), and hexanediol were supplied by Sigma Aldrich. Acetonitrile (99\% anhydrous), Acetone (99.8\% anhydrous), Tetrahydrofuran (THF) $(99.5 \%$ anhydrous), propylene carbonate $(99.5 \%$ anhydrous), dioxane (99.8\% anhydrous), ethyl acetate (99.9\% anhydrous), dichloromethane (99.9\% anhydrous), DMF (99.5\% anhydrous), DMSO (99.9\% anhydrous), 2butanone (99.9\% anhydrous), and cyclohexane were purchased from ACROS Organics ${ }^{\mathrm{TM}}$. Chemical structures of all reagents are presented in Figs 1-3.

\subsection{Characterization of PUR-PIR aerogels}

The apparent density of poly(urethane)-poly(isocyanurate) (PUR-PIR) aerogels was determined by weighing and volume measurements.

Surface area and pore volume were determined from the nitrogen adsorption-desorption isotherms at $77 \mathrm{~K}$ using a Nova 2200e Instrument (Quantachrome Corporation, USA). The samples were degassed at $130{ }^{\circ} \mathrm{C}$ for $24 \mathrm{~h}$ prior to adsorption measurements. The surface area was calculated by the Brunauer-Emmett-Teller (BET) method. The pore size distribution was determined from the desorption isotherms by using the Barett-Joyner-Halenda (BJH) method.

A Scanning Electron Microscope, Hitachi SU-70 (Hitachi Ltd., Japan), was used to image aerogel samples. Samples (about 1-mm thick) were placed on conductive carbon tabs adhered to the sample mount. A strip of adhesive copper tape, connecting with the sample and the sample mount, was placed in contact with each piece of aerogel to avoid charging during imaging. The samples were also sputter-coated with platinum, and then imaged. 
Compression tests were carried out on the universal testing machine ZwickLine Testing Machine (Zwick/Roell Group, Germany). Sample contact surfaces were cut parallel, and the samples were tested according to ASTM D695 Standard in ambient conditions. Tests were performed with a $2 \mathrm{kN}$ load cell and using a compression rate of $2 \mathrm{~mm} / \mathrm{min}$.

Dynamic mechanical analysis was determined using an ARES Rheometer (TA Instruments, USA). Torsion geometry was used with samples of thickness $2 \mathrm{~mm}$. Measurements were examined in the temperature range 20-250 ${ }^{\circ} \mathrm{C}$ at a heating rate of $10^{\circ} \mathrm{C} / \mathrm{min}$, using a frequency of $1 \mathrm{~Hz}$ and applied deformation at $0.1 \%$.

The thermal properties of the synthesized composites were evaluated by TGA measurements performed using the STA 449 F1 Jupiter Analyzer (Netzsch Group, Germany). About $10 \mathrm{mg}$ of the sample was placed in the TG pan and heated in an argon atmosphere at a rate of $10^{\circ} \mathrm{C} / \mathrm{min}$ up to<smiles>Oc1ccc(C(c2ccccc2)(c2cccc(O)c2)c2cccc(O)c2)cc1</smiles>

1,1,1-tris(hydroxyphenyl)ethane (HPE)<smiles>Oc1cc(O)cc(O)c1</smiles>

Phloroglucinol (POL)<smiles>Oc1cccc(O)c1</smiles>

Resorcinol (RES)
$600{ }^{\circ} \mathrm{C}$ with the sample mass about $10 \mathrm{mg}$. The initial decomposition temperatures, $\mathrm{T}_{10 \%}, \mathrm{~T}_{50 \%}$, and $\mathrm{T}_{80 \%}$ of mass loss were determined.

LaserComp 50 heat flow meter apparatus (LaserComp Inc., USA) with a $2.5 \times 2.5 \mathrm{~cm}$ size heat flow transducer was used to measure the thermal conductivity of PUA aerogel, which was cut into square size of $5 \mathrm{~cm} \times 5 \mathrm{~cm}$ with $1.85 \mathrm{~cm}$ thickness. The upper and lower plates of the instrument were set at 5 and $45^{\circ} \mathrm{C}$, respectively, with a mean temperature of $25^{\circ} \mathrm{C}$. Prior to testing the aerogel sample, the instrument was calibrated using a similar thermal conductivity reference sample to improve the accuracy of the measurement.

Contact angle measurements were carried out using the sessile-drop method. A manual contact angle goniometer coupled with an optical system OS-45D (Oscar, Taiwan) was used to capture the profile of a pure liquid on a solid substrate. A water drop of $1 \mu \mathrm{L}$ was deposited onto the surface using a micrometer syringe fitted with a stainless steel needle. The contact angles reported are the average of at least ten tests on the same sample.

\section{Results and discussion}

The main goal of our work was to minimize the thermal conductivity of PIR-PUR aerogels. As mentioned in the Introduction, the space of the processing parameters is vast

Fig. 1 Polyols used in the synthesis of PUR-PIR aerogels

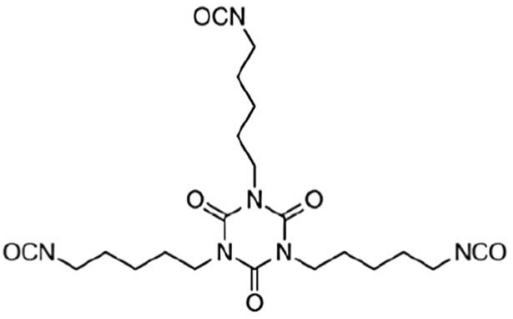

DESMODUR N3300A

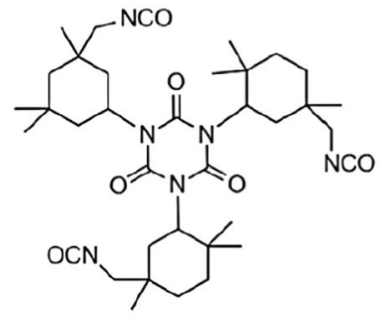

DESMODUR IL BA<smiles>O=C1C(n2c(=O)n(-c3ccc([N+](=O)[O-])cc3)c(=O)n(-c3ccc([N+](=O)[O-])cc3)c2=O)=CC=C1[N+](=O)[O-]</smiles>

DESMODUR RC

Fig. 2 Tri-isocyanates used in the synthesis of PUR-PIR aerogels

Fig. 3 Solvents used in the synthesis of PUR-PIR aerogels<smiles>CCOC(C)=O</smiles><smiles>CC#N</smiles><smiles>C1CCOC1</smiles><smiles>CC1COC(=O)O1</smiles>

Tetrahydrofuran Propylene carbonate<smiles>C1COCCO1</smiles>

Dioxane

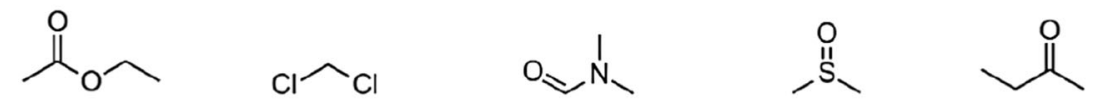

Ethyl acetate Methylene chloride Dimethylformamide Dimethylsulfoxide 2-butanone 
Table 1 Selected properties of PUR-PIR aerogels based on POL, HPE, and RES polyol

\begin{tabular}{lllllll}
\hline Sample code & $\begin{array}{l}\text { Gelation } \\
\text { time }[\mathrm{min}]\end{array}$ & Shrinkage [\%] & $\begin{array}{l}\text { Density } \\
{\left[\mathrm{g} / \mathrm{cm}^{3}\right]}\end{array}$ & $\begin{array}{l}\text { Surface area } \\
{\left[\mathrm{m}^{2} / \mathrm{g}\right]}\end{array}$ & $\begin{array}{l}\text { Pore volume } \\
{\left[\mathrm{cm}^{3} / \mathrm{g}\right]}\end{array}$ & $\begin{array}{l}\text { Pore } \\
\text { radius [nm] }\end{array}$ \\
\hline POL & 25 & 20 & 0.305 & 105 & 0.730 & 24.6 \\
HPE & 35 & 22 & 0.387 & 80 & 0.567 & 23.9 \\
RES & 60 & 29 & 0.395 & 45 & 0.430 & 32.3 \\
\hline
\end{tabular}
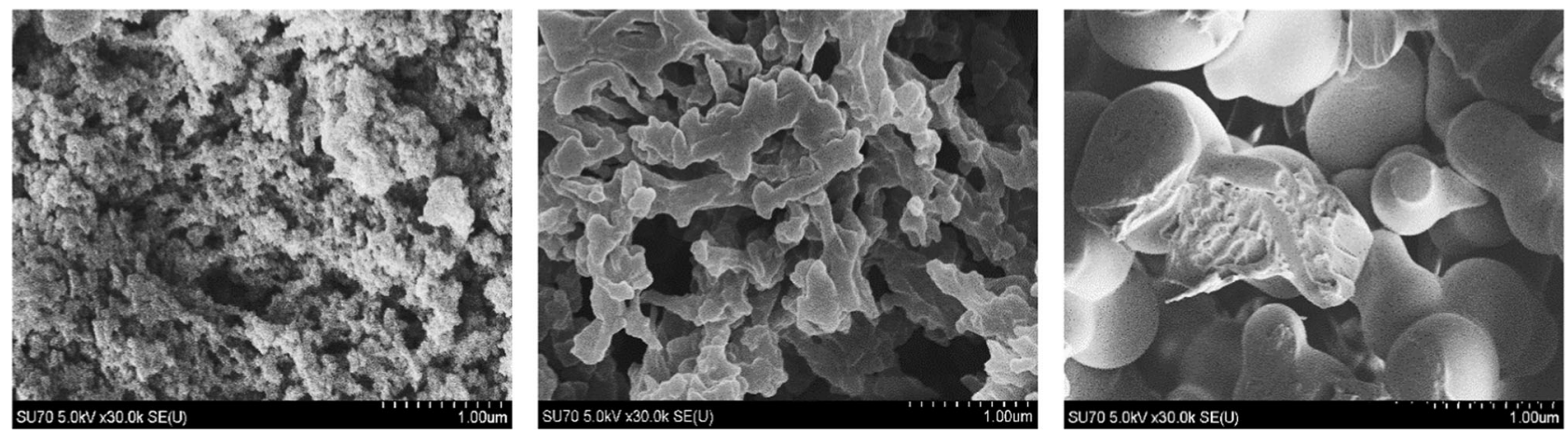

Fig. 4 Scanning electron microscopy (SEM) data of (left to right) POL, HPE, and RES-based aerogels at the same magnifications

and its analysis can be especially time-consuming if one were to measure the thermal conductivity of each sample. We note, however, that density and surface area are reasonable proxies of the thermal conductivity. Analysis of the most recent work on polyurethane-class aerogels shows that aerogels with optimum thermal conductivity have density < $\sim 0.3 \mathrm{~g} / \mathrm{cm}^{3}$ and a surface area $>100 \mathrm{~m}^{2} / \mathrm{g}$. Measurement of density and surface area is less time- and resourceconsuming than measurement of thermal conductivity. Therefore, we decided to prescreen processing conditions using density and surface area as guiding parameters. Thermal conductivity was measured only for the most promising samples.

\subsection{Role of the polyol}

In this part of the study, we report the effect of the polyol structure on the properties of PUR-PIR aerogels. We employed three trifunctional polyols, POL, HPE, and RES. PUR-PIR aerogels were obtained by the polycondensation of these polyols and tri-isocyanurate (Desmodur RC). Acetone was selected as a solvent. The reaction was catalyzed with DBTDL with a concentration of $0.6 \mathrm{wt} \%$. Except for the type of polyol (POL, HPE, or RES), all processing parameters were kept constant. After gelation, the gels were exchanged with cyclohexane (four times the volume of gel, three times every $4 \mathrm{~h}$ ) and freeze-dried at a shelf temperature of $-7{ }^{\circ} \mathrm{C}$ and a pressure $<3$ Torr. The formulations of the PUR-PIR aerogels based on the POL, HPE, and RES polyol are shown in Table S.1.
Properties of PUR-PIR aerogels based on the POL, HPE, and RES polyols are reported in Table 1 . The results indicate a dependency on polyol of density and shrinkage (POL $<$ $\mathrm{HPE}<\mathrm{RES}$ ) as well as surface areas and pore volume (POL $>$ HPE $>$ RES). Details of surface area and pore size analysis are reported in the Figs S.1 and S.2. SEM analysis is reported in Fig. 4 and shows an increase in mean particle size, which scales with the trends in density and surface area.

Specifically, POL-aerogels consist of small particles that assemble into larger globules, which in turn form even larger aggregates. For HPE-aerogels the aggregates are 5-10 times larger than those of POL-aerogels. RES aerogels are predominantly macroporous. Polymer strands have organized into spheres, which can be attributed to macroscale phase separation during gelation. For example, Malakooti et al. [24] reported that the microstructural evolution of PUR-PIR aerogels can be explained by spinodal decomposition. They showed that gelation was slower in lower concentration sols. The slower gelation rate gave time to the phase-separated polymer to undergo spheroidization. Higher concentration sols (more reactive) gelled faster and the microstructure was closer to bicontinuous. Accordingly, RES aerogels had the slowest gelation rate.

\subsection{Influence of the gelation solvent}

In this part of the work, we report the effect of the gelation solvent on the properties of PUR-PIR aerogels. PUR-PIR aerogels were synthesized by polycondensation of a polyol (POL) and a tri-isocyanurate (Desmodur ILBA). Desmodur 
Table 2 Recipes used to prepare the aerogels to study the effect of the solvent on the properties of the PUR-PIR aerogels based on the phloroglucinol and Desmodur ILBA

\begin{tabular}{|c|c|c|c|c|c|c|c|c|c|c|}
\hline \multirow[t]{2}{*}{ Sample code } & \multicolumn{2}{|l|}{ Polyol } & \multicolumn{2}{|l|}{ Isocyanate } & \multicolumn{2}{|l|}{ Catalyst } & \multicolumn{2}{|l|}{ Solvent } & \multirow{2}{*}{$\begin{array}{l}\text { Density } \\
{\left[\mathrm{g} / \mathrm{cm}^{3}\right]}\end{array}$} & \multirow{2}{*}{$\begin{array}{l}\text { Surface area } \\
{\left[\mathrm{m}^{2} / \mathrm{g}\right]}\end{array}$} \\
\hline & Name & {$[\mathrm{M}]$} & Name & {$[\mathrm{M}]$} & Name & [wt\%] & Name & {$[v / v]$} & & \\
\hline \#1 & Phloroglucinol & 0.20 & Desmodur ILBA & 0.20 & DBTDL & 0.6 & Acetone & 100 & 0.224 & 92 \\
\hline$\# 2$ & Phloroglucinol & 0.30 & Desmodur ILBA & 0.30 & DBTDL & 0.6 & Acetone & 100 & 0.321 & 105 \\
\hline \#3 & Phloroglucinol & 0.20 & Desmodur ILBA & 0.20 & DBTDL & 0.6 & Acetonitrile & 100 & 0.268 & 91 \\
\hline \#4 & Phloroglucinol & 0.30 & Desmodur ILBA & 0.30 & DBTDL & 0.6 & Acetonitrile & 100 & 0.387 & 102 \\
\hline \#5 & Phloroglucinol & 0.20 & Desmodur ILBA & 0.20 & DBTDL & 0.6 & Tetrahydrofuran & 100 & 0.157 & 1 \\
\hline \#6 & Phloroglucinol & 0.30 & Desmodur ILBA & 0.30 & DBTDL & 0.6 & Tetrahydrofuran & 100 & 0.202 & 3 \\
\hline \#7 & Phloroglucinol & 0.20 & Desmodur ILBA & 0.20 & DBTDL & 0.6 & Ethyl acetate & 100 & 0.268 & 4 \\
\hline \#8 & Phloroglucinol & 0.30 & Desmodur ILBA & 0.30 & DBTDL & 0.6 & Ethyl acetate & 100 & 0.347 & 5 \\
\hline \#9 & Phloroglucinol & 0.20 & Desmodur ILBA & 0.20 & DBTDL & 0.6 & 2-Butanone & 100 & 0.589 & 5 \\
\hline \#10 & Phloroglucinol & 0.30 & Desmodur ILBA & 0.30 & DBTDL & 0.6 & 2-Butanone & 100 & 0.698 & 7 \\
\hline \#11 & Phloroglucinol & 0.20 & Desmodur ILBA & 0.20 & DBTDL & 0.6 & Propylene carbonate & 100 & 0.505 & 1 \\
\hline \#12 & Phloroglucinol & 0.30 & Desmodur ILBA & 0.30 & DBTDL & 0.6 & Propylene carbonate & 100 & 0.587 & 2 \\
\hline$\# 13$ & Phloroglucinol & 0.20 & Desmodur ILBA & 0.20 & DBTDL & 0.6 & Dichloromethane & 100 & No gelation & \\
\hline \#14 & Phloroglucinol & 0.30 & Desmodur ILBA & 0.30 & DBTDL & 0.6 & Dichloromethane & 100 & No gelation & \\
\hline \#15 & Phloroglucinol & 0.20 & Desmodur ILBA & 0.20 & DBTDL & 0.6 & Dimethylformamide & 100 & 0.357 & 2 \\
\hline \#16 & Phloroglucinol & 0.30 & Desmodur ILBA & 0.30 & DBTDL & 0.6 & Dimethylformamide & 100 & 0.425 & 3 \\
\hline \#17 & Phloroglucinol & 0.20 & Desmodur ILBA & 0.20 & DBTDL & 0.6 & Dioxane & 100 & 0.274 & 34 \\
\hline \#18 & Phloroglucinol & 0.30 & Desmodur ILBA & 0.30 & DBTDL & 0.6 & Dioxane & 100 & 0.354 & 38 \\
\hline
\end{tabular}

ILBA was used instead of Desmodur RC because RC was unavailable in the United States for several months. Desmodur ILBA was therefore employed, having the most comparable structure to $\mathrm{RC}$ within the Desmodur family of monomers. Once Desmodur RC became available, some of the experiments presented in this section were repeated and found to coincide with the results obtained with Desmodur ILBA. Similarly, experimentation was also carried out in selected solvents using the polyols reported in "Role of the polyol" section. The results were comparable with those of "Role of the polyol" section and indicated that POL yielded the best materials, independent on the solvent.

Two monomer concentrations were investigated, 0.2 and $0.3 \mathrm{M}$, respectively. PUR-PIR gels were prepared with different solvents as well as solvent blends. The Hansen solubility parameters of the solvents are reported in Table S.2. Apart from the gelation solvent, all processing parameters were kept constant. The gels were freeze-dried following the procedure reported in "Role of the polyol" section. The compositions of the precursor solution for single solvents and solvent blends are reported in Tables 2 and 3, respectively, together with the physical properties of the materials. Digital camera images of PUR-PIR aerogels are shown in Fig. S.3. The results of the BET analysis are presented in Figs S.4 and S.5.

The relationship between the Hansen parameters of the solvent (or solvent blend) and aerogel density and surface area is shown in Figs 5 and 6, respectively. Figure 5a indicates that aerogel density increases as $\delta_{\mathrm{D}}$ increases. The dependence on $\delta_{\mathrm{D}}$, however, is weak. One can only safely state that the density is $>0.4 \mathrm{~g} / \mathrm{cm}^{3}$ when $\delta_{\mathrm{D}}>18.4 \mathrm{MPa}^{1 / 2}$. For smaller values of $\delta_{\mathrm{D}}$, the density can be anywhere between $\sim 0.2$ and $\sim 0.4 \mathrm{~g} / \mathrm{cm}^{3}$. No apparent correlation is evident between $\delta_{\mathrm{H}}, \delta_{\mathrm{P}}$ and sample density (Fig. 5b, c). As for surface area (Fig. 6), the data scatter is considerable and prevents to draw any conclusions.

To further illustrate the weak dependence of density and surface area on solubility parameters, let us compare samples \#19 and \#20 of Table 3. Sample \#19 was prepared in a solvent blend of THF and acetonitrile (50:50\% $\mathrm{v} / \mathrm{v})$. It had a surface area of $207 \mathrm{~m}^{2} / \mathrm{g}$ and a density of $320 \mathrm{~g} / \mathrm{cm}^{3}$. Sample \#20 was prepared in a blend of THF and acetone $(50: 50 \% \mathrm{v} / \mathrm{v})$. The mixture has Hansen parameters which are extremely comparable with that of sample \#19, see also Table S.2. Yet, the surface area of sample \#19 was $10 \mathrm{~m}^{2} / \mathrm{g}$ and the density was $230 \mathrm{~g} / \mathrm{cm}^{3}$. We also note that solubility parameters indicated as optimal by previous work yield mediocre results for our particular system. Both Rigacci and Koebel $[6,8]$ reported that $\delta_{\mathrm{D}}$ between 16 and $17 \mathrm{MPa}^{1 / 2}$ yielded the best results. Yet, samples \#23 and \#24, which had $\delta_{\mathrm{D}}=15.9$ and 16.3, respectively, had a surface area $<10 \mathrm{~m}^{2} / \mathrm{g}$, which makes them hardly classifiable as aerogels. Therefore, solubility parameters are not accurate predictors of aerogel properties for our particular system. 


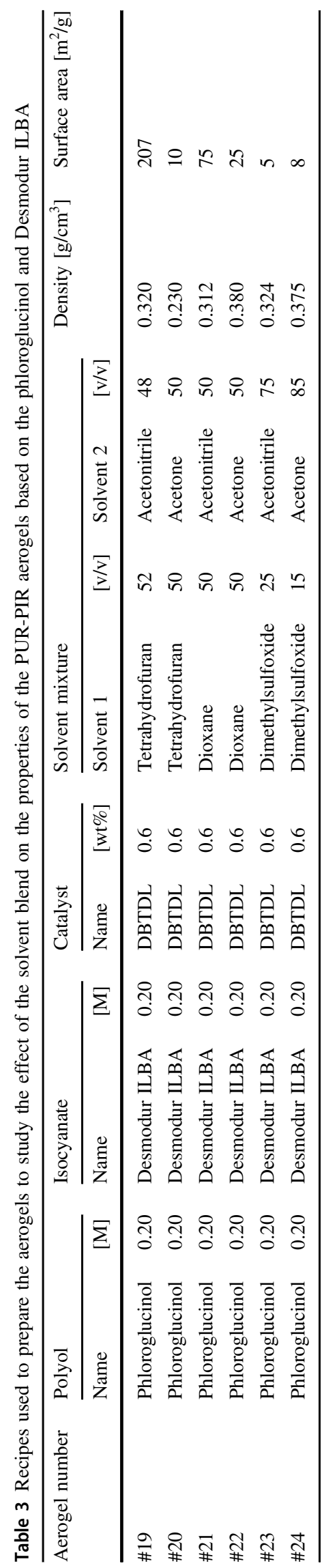

The structural evolution as a function of the solvent composition can also be monitored by SEM. Figure 7a, b shows that aerogel prepared in a THF:ACN mixture (\#19) has a mesoporous microstructure [7]. Aerogels prepared in Dioxane: ACN and DMSO:ACN blends (samples \#21 and \#23, respectively) have a macroporous structure. Figure $7 \mathrm{c}-\mathrm{f}$ shows that the polymer has organized into coarse spheres, indicating macroscale phase separation during gelation. Overall, the results indicate a complex and unclear relationship between solvent type, microstructure, surface area, and density. Bulk polymerization experiments are about as inconclusive as our experiments on aerogels. For example, Kothandaraman and Nasar [19] showed that for dibutyltin catalyzed reactions, solvents did affect polymerization rate, but no clear dependence on hydrogen bonding index, the dielectric constant of electron donor number could be identified. The unclear dependence of polymerization rate (which in turn can affect aerogel morphology) on processing parameters might be related to formation complexes between hydroxyl groups, tin catalyst, and isocyanates. Binary $(\mathrm{Sn}-\mathrm{OH})$ and ternary complexes ( $\mathrm{Sn}-\mathrm{OH}-\mathrm{NCO}$ ) have been reported by several authors (see, for example, [20, 21]). Structure and concentration of these complexes appear to depend on the solvent (which may coordinate with the reagents or the catalyst). However, the complexes are often short-lived and difficult to characterize. Our conclusion is that solvent effects are extremely difficult to anticipate. More work on bulk polymerization might be necessary to help with aerogel efforts.

\subsection{Influence of isocyanate monomer structure and concentration}

In this part of the study, we report on the effect of the isocyanate structure and concentration on the properties of PURPIR aerogels. We tested three trifunctional isocyanates: aromatic Desmodur ILBA (IPDI), Desmodur RC (which is based on TDI), and the aliphatic N3300A (HDI). Aerogels were obtained by the polycondensation of polyol and triisocyanurate. Three monomer concentrations were investigated, $0.1 \mathrm{M}, 0.2 \mathrm{M}$, and $0.3 \mathrm{M}$, respectively. Based on the results presented in "Role of the polyol" and "Influence of the gelation solvent" sections, POL was chosen as polyol and the solvent was a blend of acetonitrile and THF (50:50\% v/v). Apart from the isocyanate structure, all processing parameters were kept constant. The gels were freeze-dried as described in "Role of the polyol" section. The composition of the parent solutions is reported in Table S.3, and the properties of the aerogels are reported in Table 4.

\subsubsection{Gelation time}

N3300A-based samples gelled much more slowly $(>3 \mathrm{~h})$ than the corresponding samples based on ILBA (25-45 min) and 

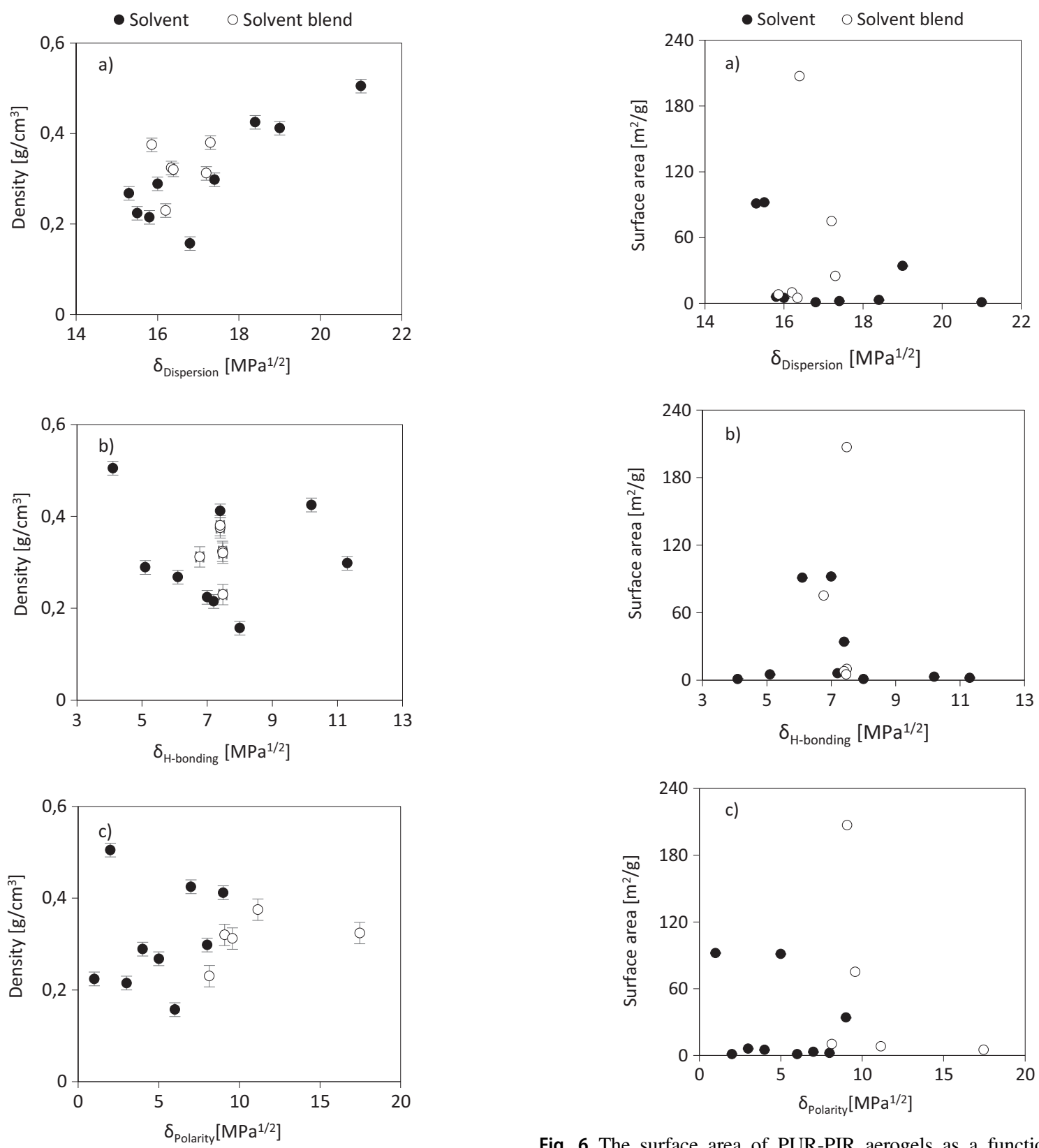

Fig. 5 The density of PUR-PIR aerogels as a function of the Hansen solubility parameter

$\mathrm{RC}(15-30 \mathrm{~min})$. The longer gelation time is due to the lower reactivity of aliphatic (HDI) versus aromatic (IPDI and TDI) isocyanates [12]. For all monomers, gelation time decreases when monomer concentration is increased. This is understandable since polymerization of urethane is first order in both isocyanate, polyol, and catalyst concentration $[25,26]$.

\subsubsection{Shrinkage}

Digital camera images of aerogels prepared in this part of the study are presented in Fig. S.6. All aerogels shrank during all fabrication steps: gelation (up to 7\%), solvent

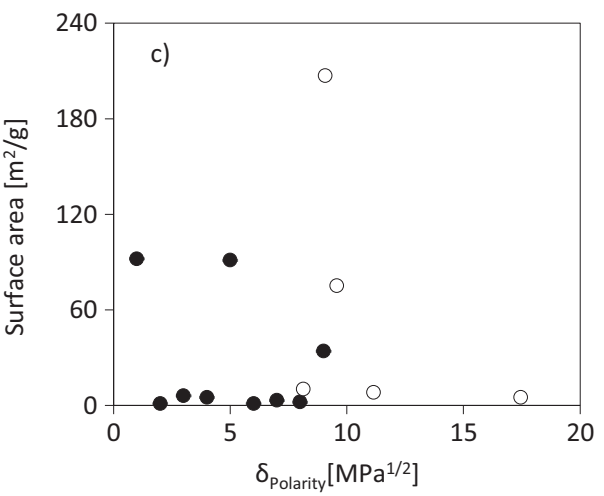

Fig. 6 The surface area of PUR-PIR aerogels as a function of the Hansen solubility parameters

exchange (up to 16\%), and drying (up to 17\%). Shrinkage is due to the van der Waals interaction between noncovalently bonded polymeric segments. Shrinkage is common in polymers, including organic aerogels, and it is due to the formation of hydrogen bonds between polymer strands. There are, however, interesting dependencies on monomer type and concentration. Aerogels prepared with the N3330A monomer shrank $35-38 \%$. This shrinkage is higher than that of the aromatic monomers $(<30 \%)$, likely due to the inherent flexibility of the $-\left(\mathrm{CH}_{2}\right)_{6}-$ tethers of N3330A. Shrinkage of aerogels prepared with Desmodur ILBA was between 17 and $30 \%$, which was slightly higher than that of aerogels prepared with the more rigid Desmodur RC 

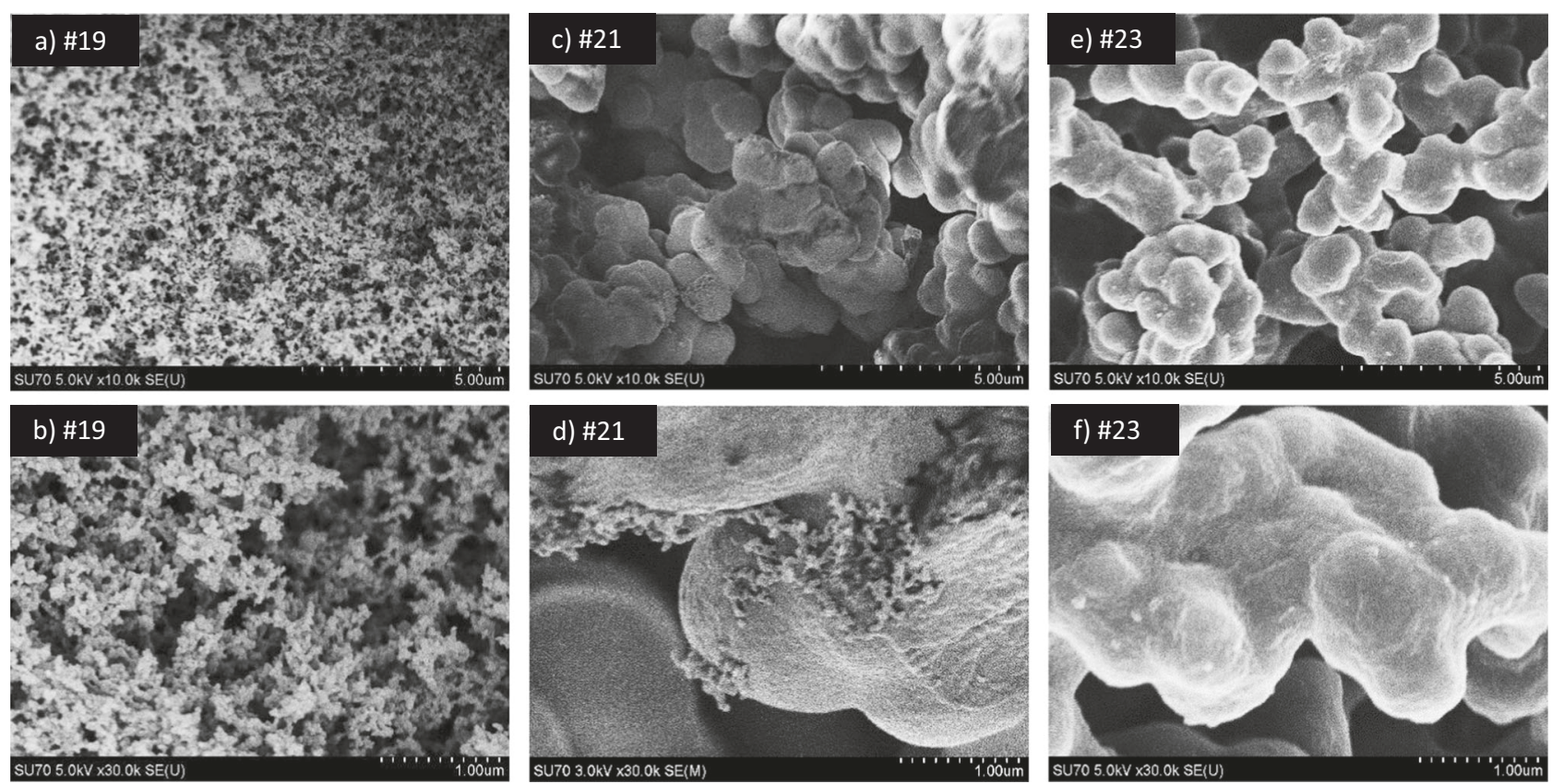

Fig. 7 Scanning electron microscopy (SEM) data of sample a, b \#19 $\left(\delta_{\text {Dispersion }}=16.4 \mathrm{MPa}^{1 / 2}, \delta_{\text {Polarity }}=9.1 \mathrm{MPa}^{1 / 2}, \delta_{\mathrm{H} \text {-bonding }}=7.5 \mathrm{MPa}^{1 / 2}\right)$, c, d \#21 ( $\delta_{\text {Dispersion }}=17.2 \mathrm{MPa}^{\mathrm{I} / 2}, \delta_{\text {Polarity }}=9.6 \mathrm{MPa}^{1 / 2}, \delta_{\text {H-bonding }}=6.8$

$\left.\mathrm{MPa}^{1 / 2}\right)$ and e, f \#23 $\left(\delta_{\text {Dispersion }}=16.3 \mathrm{MPa}^{1 / 2}, \delta_{\text {Polarity }}=17.5 \mathrm{MPa}^{1 / 2}\right.$, $\delta_{\text {H-bonding }}=7.5 \mathrm{MPa}^{1 / 2}$ )

(12-26\%). Aerogel shrinkage also depended on isocyanate concentration, as shown in Fig. 8. For all monomers, samples shrank up to $40 \%$ less as the monomer concentration increased, likely due to a higher degree of cross-linking between polymer strands. Overall, the shrinkage of our PURPIR aerogels is comparable or somewhat lower than reports on polymeric aerogels, where shrinkages of up to $46 \%$ have been reported [27-30]. We also note that freeze-drying did not induce a large difference in shrinkage compared with the literature reports (where aerogels were supercritically dried), indicating that shrinkage is mostly due to the interaction between polymer strands during processing and drying.

\subsubsection{FT-IR analysis}

FT-IR spectra of PUR-PIR aerogels are shown in Fig. 9a-c. The characteristic bands of PU are summarized in Table 5 .

The urethane moieties of PUR-PIR aerogels are confirmed by the presence of the characteristic bands of the $v$ $(\mathrm{C}=\mathrm{O})$ vibration $\left(1700-1770 \mathrm{~cm}^{-1}\right)[31,32], \quad v(\mathrm{~N}-\mathrm{H})$ stretching vibration $\left(3200-3600 \mathrm{~cm}^{-1}\right)[33,34]$ and $\delta(\mathrm{N}-\mathrm{H})$ bending vibration $\left(1590 \mathrm{~cm}^{-1}\right)$ [35]. The relative position of the main characteristic bands for various functional groups of PUR-PIR is comparable for all samples. Importantly, neither the $v(\mathrm{~N}=\mathrm{C}=\mathrm{O})$ stretching vibration in the 2273 $-2000 \mathrm{~cm}^{-1}$ range nor the urea carbonyl stretch in the 1600 $-1640 \mathrm{~cm}^{-1}$ range or the intense $v(\mathrm{O}-\mathrm{H})$ stretch of the monomer in the $3200-3350 \mathrm{~cm}^{-1}$ range was detectable, supporting complete reaction of $\mathrm{NCO}$ with $\mathrm{OH}$ to urethane.

\subsubsection{Surface area, pore size, and pore volume}

The $\mathrm{N}_{2}$ adsorption-desorption isotherms of PUR-PIR aerogels are shown in Fig. S.7 and can all be classified as IUPAC type IV. Surface areas and pore volumes calculated with the BET (BJH, respectively) method are reported in Table 4. Aerogels based on the aliphatic isocyanate N3300A have lower surface areas than their aromatic (ILBA and RC) counterparts, which is likely related to their larger shrinkage. As for pore sizes, Fig. S.8, we note a shift towards smaller pores and an increase in pore volume for increasing monomer concentration.

\subsubsection{Morphology}

The morphologies of the aerogel monoliths were examined using SEM and images are shown in Fig. 10. The aerogels present a granular structure at low monomer concentrations. When the concentration is increased, however, coalescence into ribbon-like aggregates is noticed, which is most evident in the $\mathrm{N}$-series.

High magnification images (Fig. 11) show that RC aerogels have a very fine structure, with particles connected by small necks. The structure becomes increasingly coarse, 


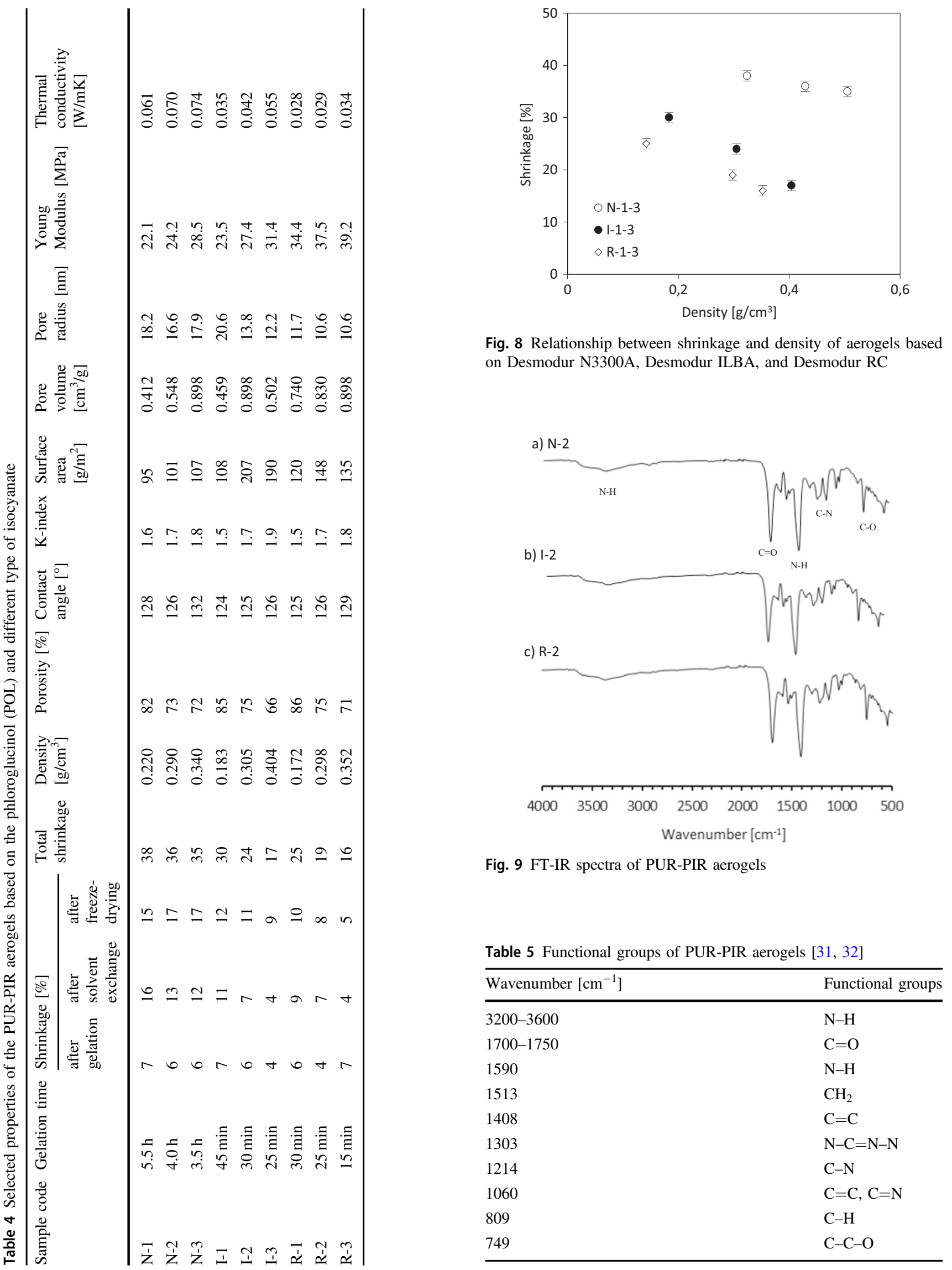



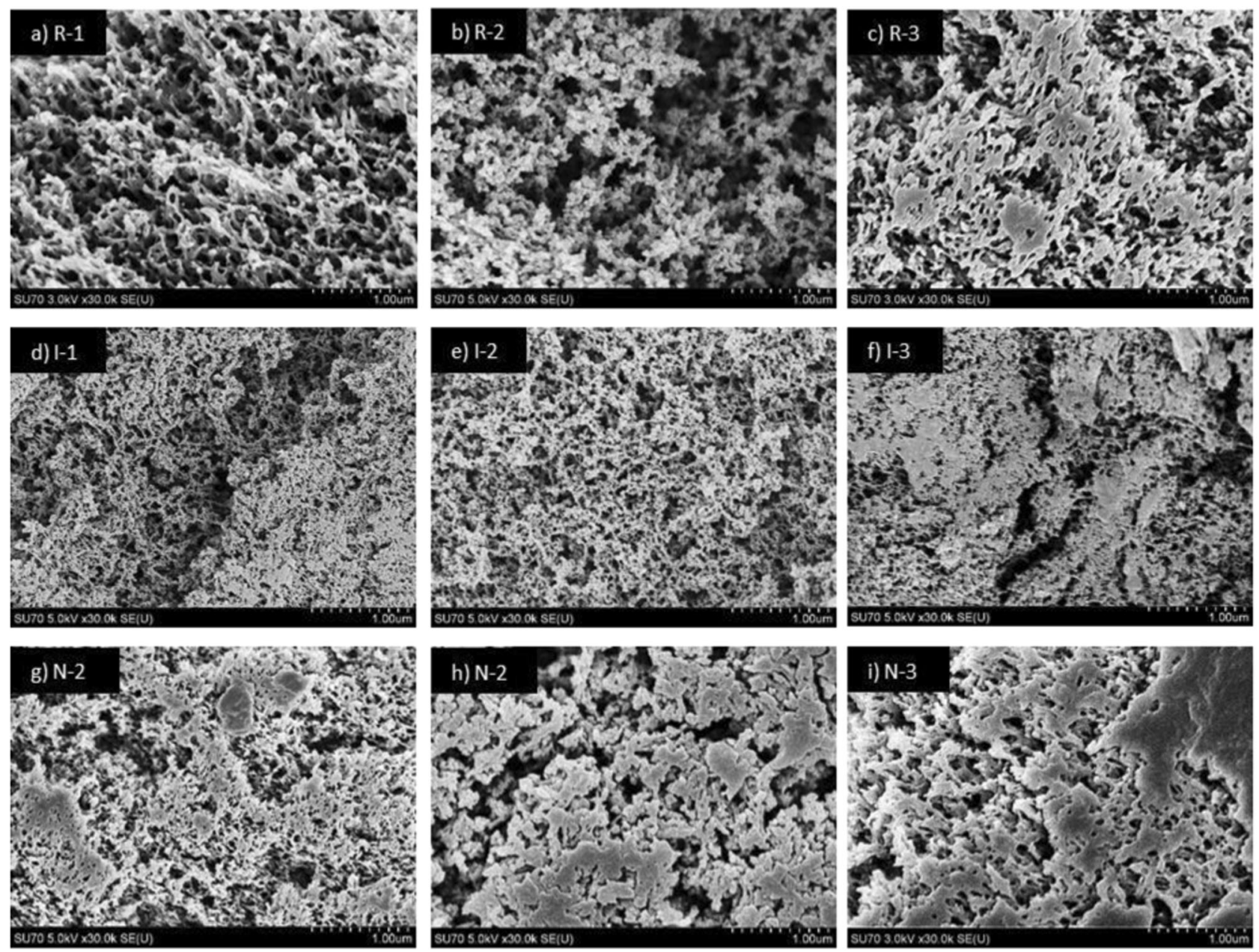

Fig. 10 SEM images of PUR-PIR aerogels at a magnification of $\times 30,000$
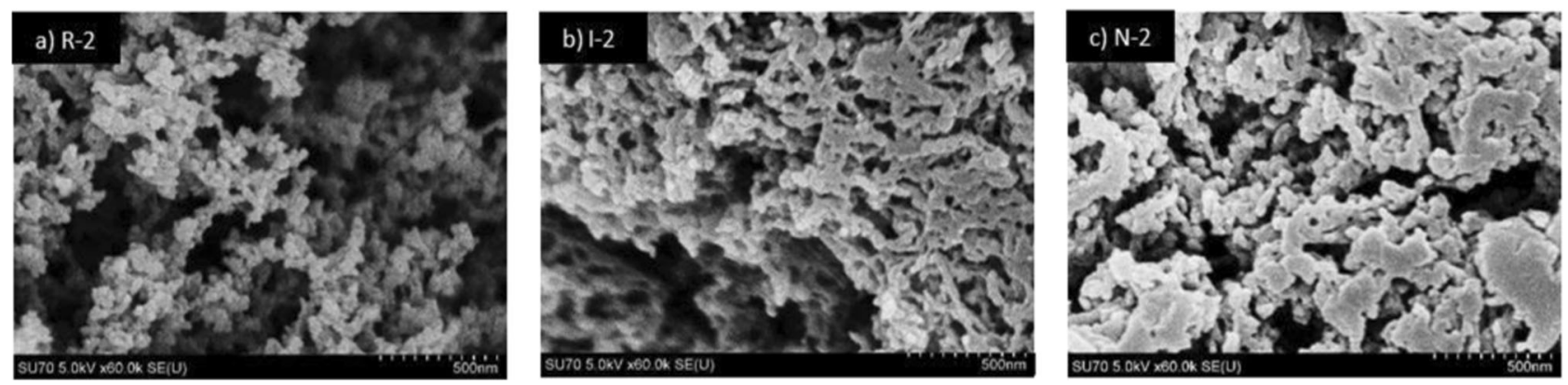

Fig. 11 Representative SEMs of samples a R-2, b I-2, and $\mathbf{c}$ N-2 at a magnification of $\times 60,000$

and the interconnecting necks larger, in samples with less rigid monomers (ILBA, and, most evidently, N3300A).

\subsubsection{Compression modulus}

Compression tests were performed following the procedure described in the experimental section. The data are reported in Fig. S.9 and Table S.4. Stress-strain curves are shown in Fig. 12. All curves exhibit three stages of deformation: linear stage, in which reversible deformation occurs and the slope of the curve yields Young's modulus $(E)$, yield stage, in which the framework of the aerogel begins to collapse and irreversible deformation occurs, and densification stage, in which the structure of the aerogel becomes dense and the 

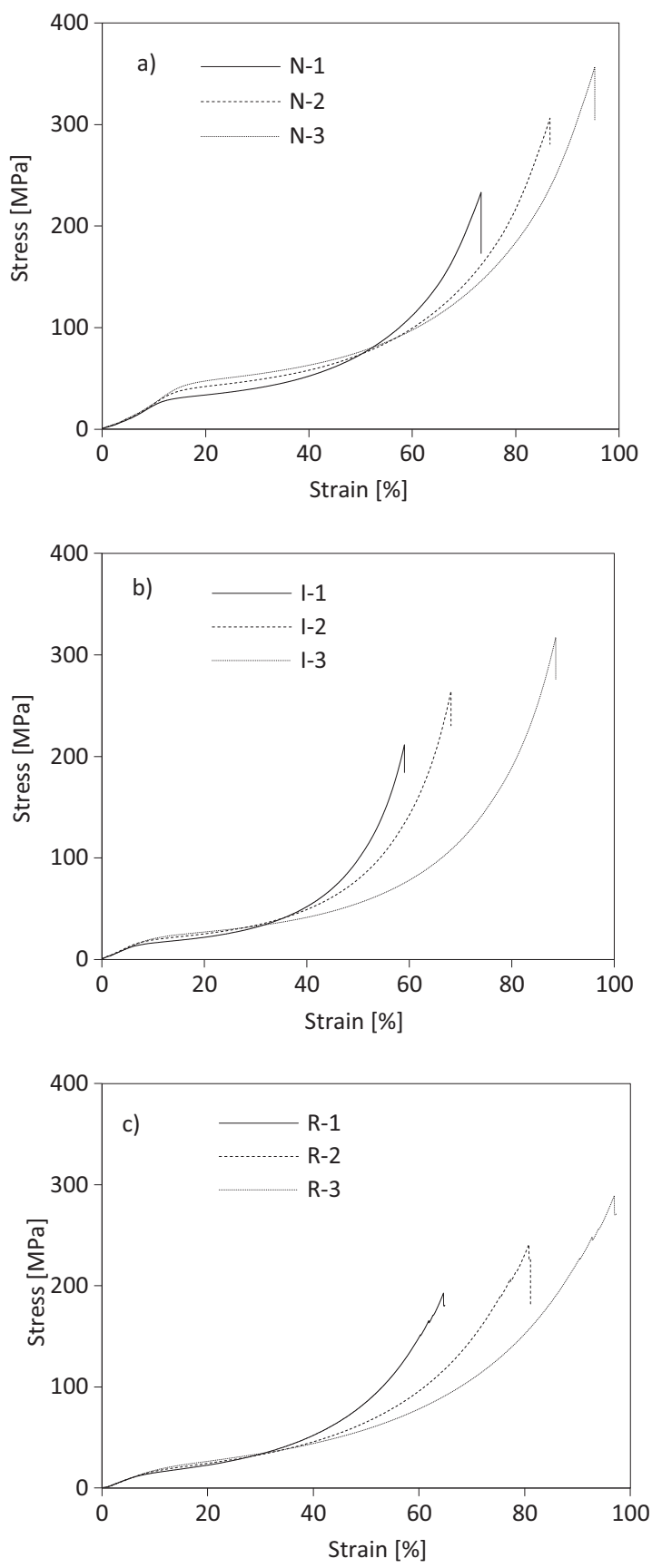

Fig. 12 Stress-strain curves plotted for PUR-PIR aerogels

stress increases sharply with increasing strain [36-39]. In all cases, the stress-strain curves of samples with a higher concentration of isocyanate exhibit a sharp transition from the linear to the plateau region. Less-concentrated samples are characterized by a more smooth transition which indicates a greater ductility of the materials.

The values of Young's modulus $(E)$ are reported in Table 4. As is often the case for aerogels [71-76], the compression

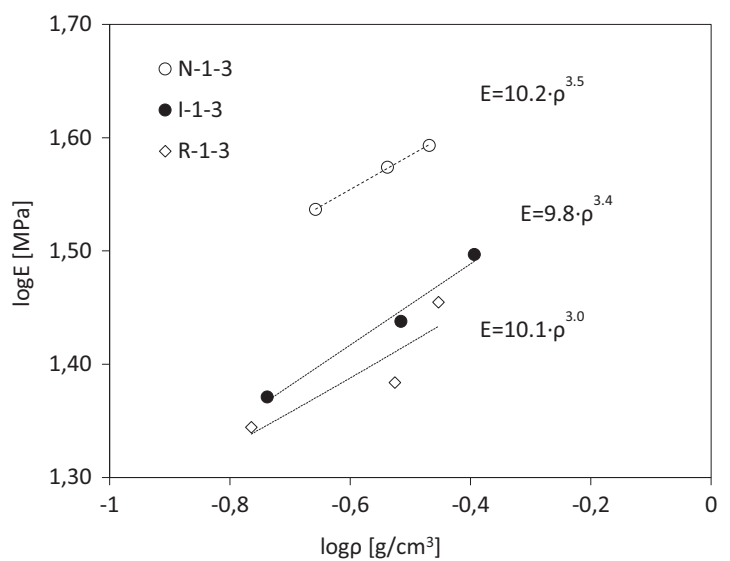

Fig. $13 \log -\log$ plot of $E$ as a function of aerogel density $\rho$

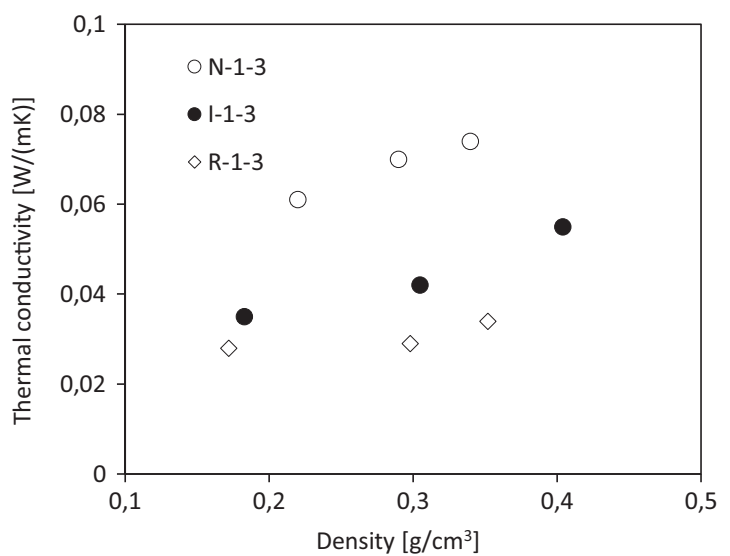

Fig. 14 Thermal conductivity of the PUR-PIR aerogels as a function of density

modulus $E$ and the density $\rho$ are related by a power law:

$E=E_{0}(\rho)^{m}$,

where $E$ is Young's modulus (MPa) and $\rho$ is the density of the aerogel $\left(\mathrm{kg} / \mathrm{m}^{3}\right)$. Best-fit of Eq. (2) to the data of Fig. 13 yields an exponent $m$ between 3.0 and 3.5, in overall agreement with previous results on this class of materials [7, 40, 41].

We also note that the compression modulus is the lowest for N3300A-based aerogels and the highest for RC-based aerogels. This is not surprising given the different rigidity of the monomers.

\subsubsection{Thermal conductivity}

Thermal conductivity of RC, ILBA, and N3300A-based aerogels are reported in Fig. 14 as a function of aerogel density. The data show that thermal conductivity increases 
with density. This is not unexpected, since in aerogels conduction through the skeleton is the most relevant contribution to the total thermal conductivity (convection being suppressed by the mesopores). For example, a compilation of data from Leventis' recent work on polyurea [7], reported in Fig. 15, shows that thermal conductivity increases almost linearly with aerogel density.

The thermal conductivity of our materials compares well with literature reports for this class of aerogels. For example,

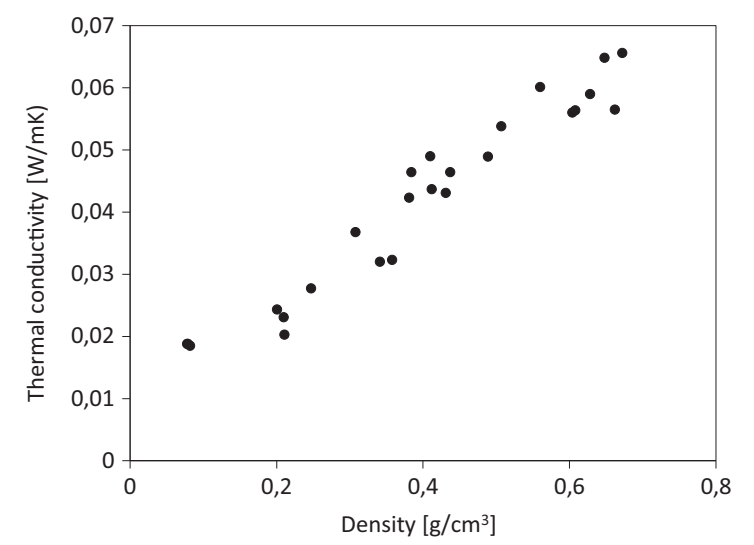

Fig. 15 Compilation of Leventis' data for polyurea synthesized with THF as gelation solvent [7] isocyanate aerogels based on methylidynetri-p-phenylene triisocyanate (Desmodur RE) and a difunctional polyol were produced by supercritical drying by Henkel [42] and had a thermal conductivity in the range of $0.038-0.071 \mathrm{~W} / \mathrm{mK}$. Similarly, most formulations by Leventis, Koebel, Rigacci, and Chidambareswarapattar yielded materials with thermal conductivities between 0.025 and $0.030 \mathrm{~W} / \mathrm{mK}[6-8,22]$.

\subsubsection{Can we find a predictive parameter?}

In "Influence of the gelation solvent" section, we showed that unfortunately, the solubility parameters of the gelation solvent are not a good predictor of the outcome for our system. Hence we investigated the relation between $K$-index (defined as the ratio of contact angle to porosity) and aerogel properties [23]. Since we could not measure porosity via He pycnometry (not available in our laboratory), we used the standard formula $\pi=100 \times\left(\rho_{s}-\rho_{b}\right) / \rho_{s}$, where $\pi$ is the porosity, $\rho_{b}$ the density of the aerogel, and $\rho_{s}$ the skeletal density. Previous work has shown that skeletal density of polyurea aerogels does not vary strongly between samples. Hence, we assumed a constant value $\rho_{s}=1.23 \mathrm{~g} / \mathrm{cm}^{3}$, in accordance with previous reports [7]. Surface area, thermal conductivity, and compression modulus are reported in Fig. 16 as a function of the
Fig. 16 Selected properties of PUR-PIR aerogels as a function of the $K$-index values
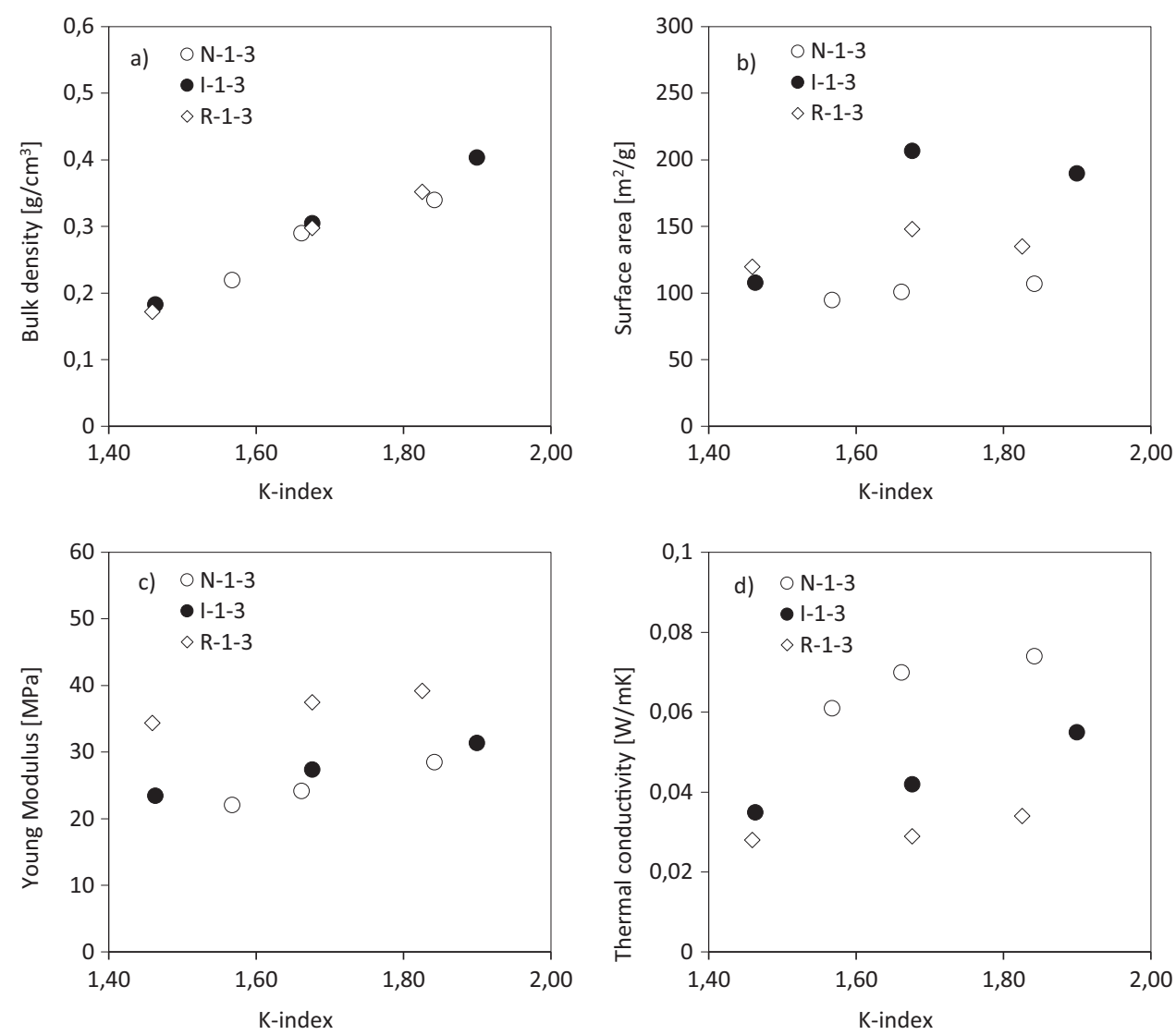
Fig. 17 On the search for a predictive parameter: a Shrinkage vs. density. b Surface area vs. shrinkage. c Thermal conductivity vs. shrinkage. d Thermal conductivity vs. (shrinkage $\times$ density)
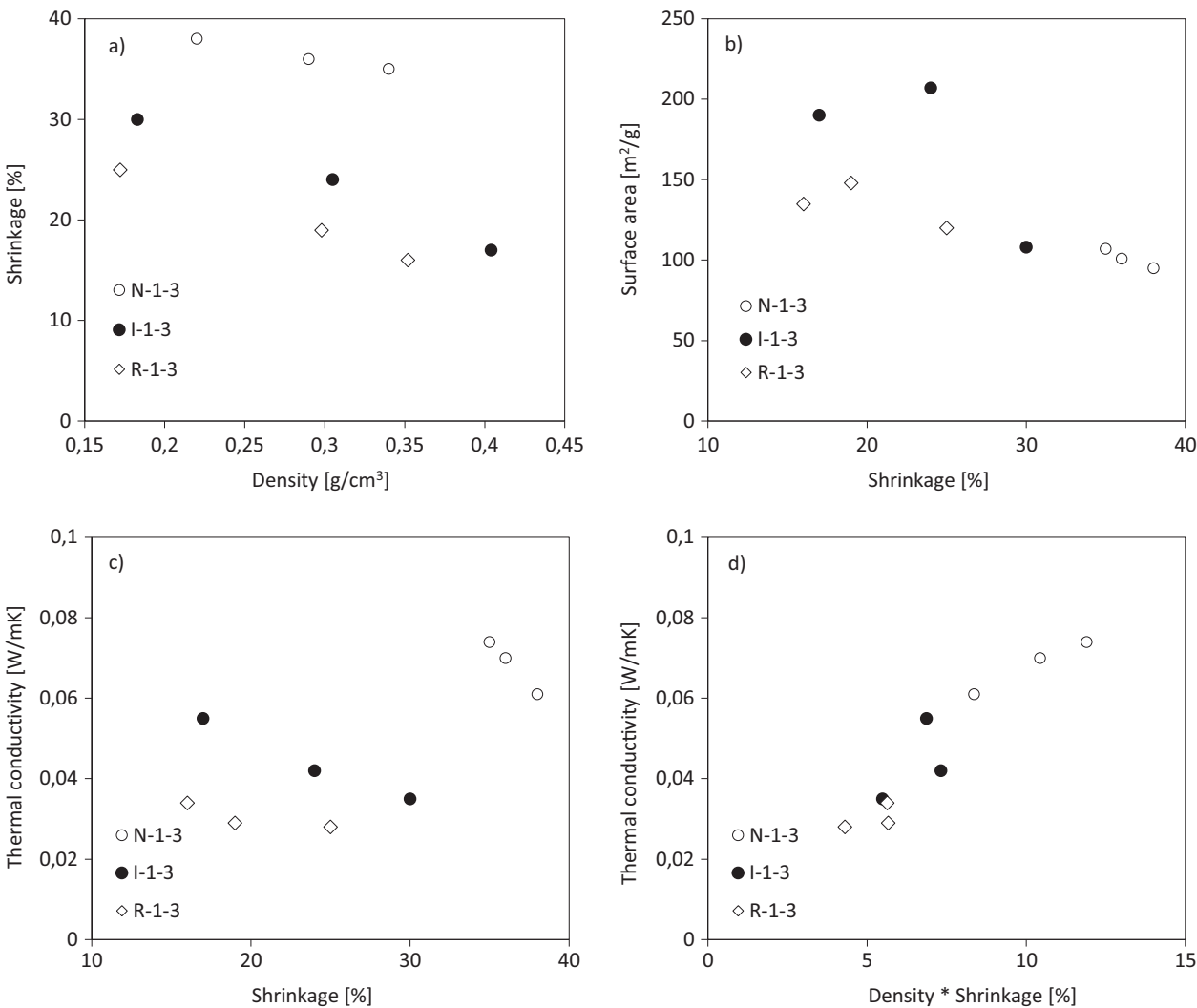

K-index, which is also reported in Table 4. Figure 16a indicates that aerogel density increases as $K$-index increases. This is expected since in our samples the contact angle is very comparable. Hence, the $K$-index is simply proportional to the density of the samples. Surface area (Fig. 16b), Young's modulus (Fig. 16c), and thermal conductivity (Fig. 16d) do indeed scale with the K-index (or, for that matter, with density). However, each of the series (i.e., each isocyanate monomer) lies on a different curve.

We thus wondered if it were possible to find a parameter that could predict the thermal conductivity independent of the monomer. Our reasoning is best discussed in conjunction with Fig. 17. We first noticed that shrinkage decreased somewhat with increasing density (Fig. 17a). The lower shrinkage at higher density is related to the higher modulus of denser aerogels, see Fig. 13. We then looked at the dependence of surface area on shrinkage (Fig. 17b). Surface area decreases, albeit not strongly, with increasing shrinkage. This is also expected since higher shrinkage brings skeletal nanoparticles closer to each other and reduces surface area. We then analyzed the dependence of thermal conductivity on shrinkage (Fig. 17c). Thermal conductivity decreases with increasing shrinkage. This makes sense since samples with higher shrinkage have lower density and therefore lower thermal conductivity. While the data of Fig. 17a-c can be explained, we still note that the trends depend on the monomer. However, when one plots thermal conductivity against the product of density and shrinkage (Fig. 17d), the dependence on the monomer is alleviated. The explanation is as follows. Aerogels prepared out of flexible monomers (Desmodur N3300) exhibit a lot of shrinkage (35-40\%), which in turn results in aggregation of the skeletal nanoparticles into ribbonlike structures, as shown in the SEM images of Fig. 10. These ribbon-like structures act as thermal bridges and increase thermal conductivity. Aerogels prepared out of rigid monomers (Desmodur $\mathrm{RC}$ ), instead, maintain a granular structure and their thermal conductivity is up to two times lower than that of the flexible $\mathrm{N}$-series for the same density.

\subsubsection{Dynamic mechanical analysis}

The dynamic mechanical behavior of PU-PIR aerogels as a function of the temperature is shown in Fig. 18. It is notable that more concentrated samples are characterized by higher storage modulus $\left(E^{\prime}\right)$. The modulus difference is more noticeable at low temperatures, where the materials are stiff (e.g., the high-density storage module is about three times higher than low density corresponding values at $50^{\circ} \mathrm{C}$, 

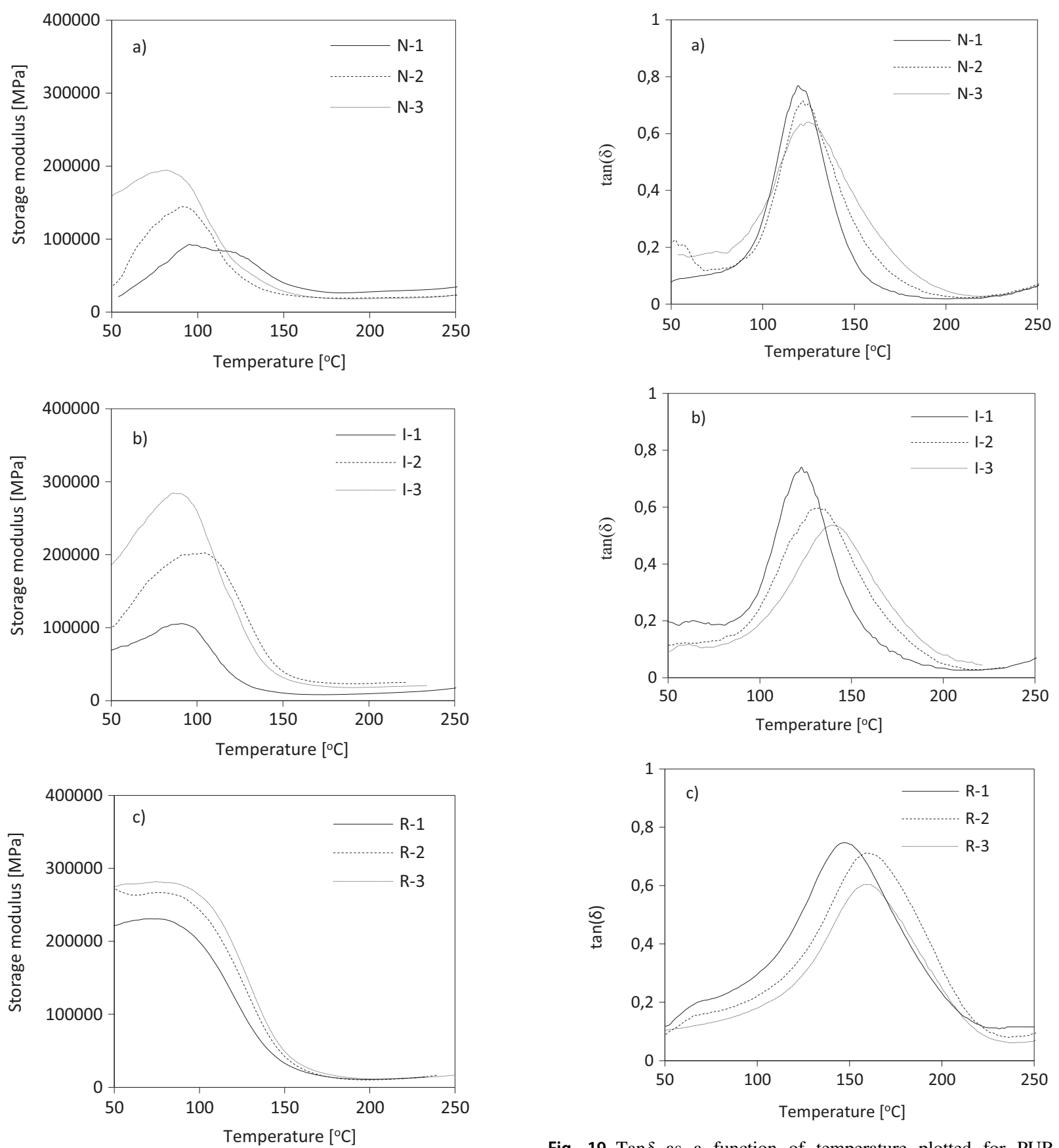

Fig. 18 Storage modulus as a function of temperature plotted for PURPIR aerogels

respectively). This improvement in $E^{\prime}$ is attributed to the beginning of a thermal transition, which is associated with hard segments phase. The changes observed around $100{ }^{\circ} \mathrm{C}$ are attributable to the presence of a high concentration of hydrogen-bonded aromatic urethane groups in the poly (ether-urethane) phase and hard-segment domains which act as macroscopic cross-links. The higher $E$ ' for more concentrated samples indicates more restricted mobility compared with the less-concentrated, thus, the lower

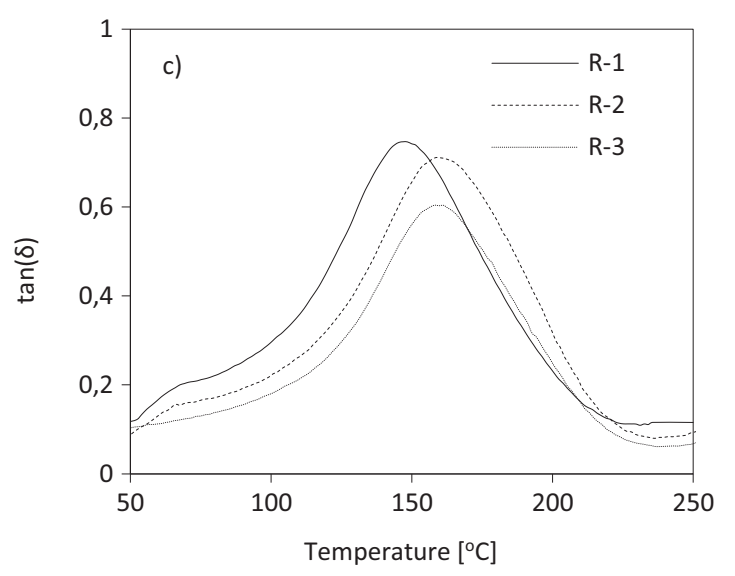

Fig. $19 \operatorname{Tan} \delta$ as a function of temperature plotted for PUR-PIR aerogels

concentration of isocyanate produces more flexible materials. Overall, the composites show a marked improvement in modulus with increasing isocyanate concentration. Among the used isocyanates, the best properties possess samples R$1-3$, as a result of more pronounced rigidity of the polymer backbone, as compared with the samples I-1-3, and N-1-3.

The results presented in Fig. 19 and Table 6, indicate that the structure of isocyanate and the concentration of monomers affect the value of the glass transition temperature $\left(T_{g}\right)$, 
Table 6 The results of thermogravimetric analysis of PUR-PIR aerogels

\begin{tabular}{lllll}
\hline Sample code & $T_{g}\left[{ }^{\circ} \mathrm{C}\right]$ & $T_{10}\left[{ }^{\circ} \mathrm{C}\right]$ & $T_{50}\left[{ }^{\circ} \mathrm{C}\right]$ & $T_{70}\left[{ }^{\circ} \mathrm{C}\right]$ \\
\hline N-1 & 121 & 239 & 321 & 468 \\
N-2 & 122 & 243 & 332 & 484 \\
N-3 & 126 & 255 & 340 & 494 \\
I-1 & 124 & 240 & 332 & 470 \\
I-2 & 138 & 257 & 341 & 500 \\
I-3 & 143 & 260 & 349 & 513 \\
R-1 & 148 & 245 & 331 & 469 \\
R-2 & 165 & 263 & 347 & 502 \\
R-3 & 167 & 265 & 355 & 522 \\
\hline
\end{tabular}

which corresponds to the maximum value of the curve loss tangent $(\tan \delta)$ versus temperature. Compared with the PURPIR aerogels based on the aliphatic isocyanate, their aromatic isocyanate counterparts are characterized by higher $T_{g}$. As expected, in all cases, more concentrated samples are characterized by a higher value of $T_{g}$. Wu et al. [43] have shown that the $T_{g}$ of PUR-PIR reflects the rigidity of the polymer matrix which is a function of the isocyanate index, cross-link density and aromaticity level of the samples. Given that, the increase in the $T_{g}$ must be a reflection of the increased aromaticity and cross-link density due to a higher number of thermally stable urethane bonds as well as a more dense structure of the aerogels.

\subsubsection{Thermogravimetric analysis}

Due to their excellent thermal insulation properties, PURPIR aerogels and foams are often used in the construction industry. For building applications, thermal stability is important. Thermogravimetric analysis was therefore performed to investigate the effect of the isocyanate concentration and isocyanate structure on the thermal performance of the PUR-PIR aerogels (Fig. 20).

The decomposition of all PUR-PIR aerogels consists of three stages (Fig. 21). The first step of decomposition is connected with dissociation of urethane bond at a temperature between 150 and $330{ }^{\circ} \mathrm{C}$ (corresponding to the temperature at $10 \%$ of total weight losses) [44, 45]. The second step of the degradation of PUR-PIR aerogels occurs at the temperature between 330 and $400{ }^{\circ} \mathrm{C}$ and is ascribed to the decomposition of soft polyol segments (corresponding to the temperature at $50 \%$ of total weight losses) [46]. The third step of degradation corresponds to a weight loss of about $70 \%$, occurs at a temperature of $\sim 500{ }^{\circ} \mathrm{C}$ and it is ascribed to the degradation of the fragments generated during the second step [44, 47].

The structure of the monomers affects only minimally the thermal stability of the PUR-PIR aerogels (Table 6). The degradation stage of the aerogels N-1-3 starts at 239-255 ${ }^{\circ} \mathrm{C}$, while the aerogels I-1-3 and R-1-3 start to
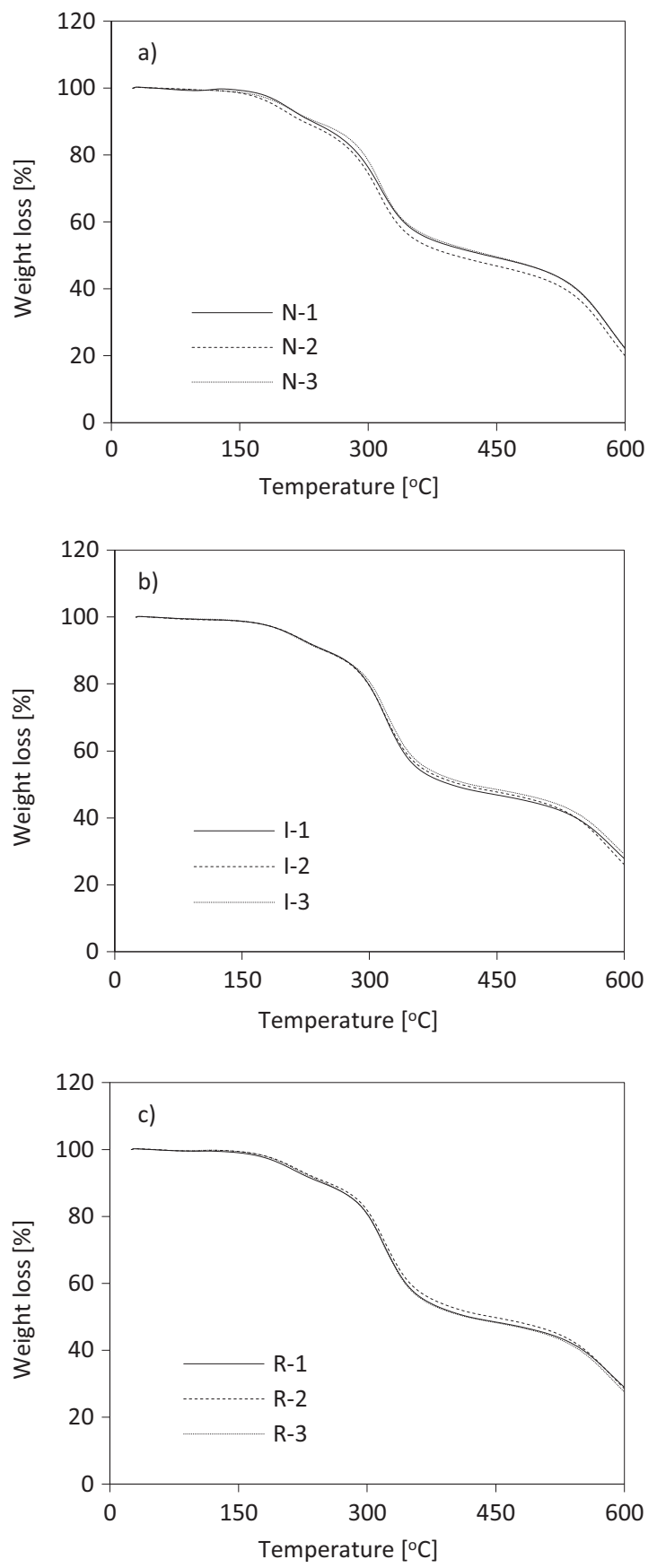

Fig. 20 TGA curves plotted for PUR-PIR aerogels

degrade at a slightly higher temperature, in the range of $240-265^{\circ} \mathrm{C}$. In all cases, the influence of monomers concentration is observed. For the most concentrated samples, one observes increased thermal stability, which may be due to a higher number of thermally stable urethane bonds as well as a more dense structure of the aerogels. Remarkably, the aerogels are more thermally stable than their closed-cell foam counterparts. For example, for sample R-3, thermal degradation starts 

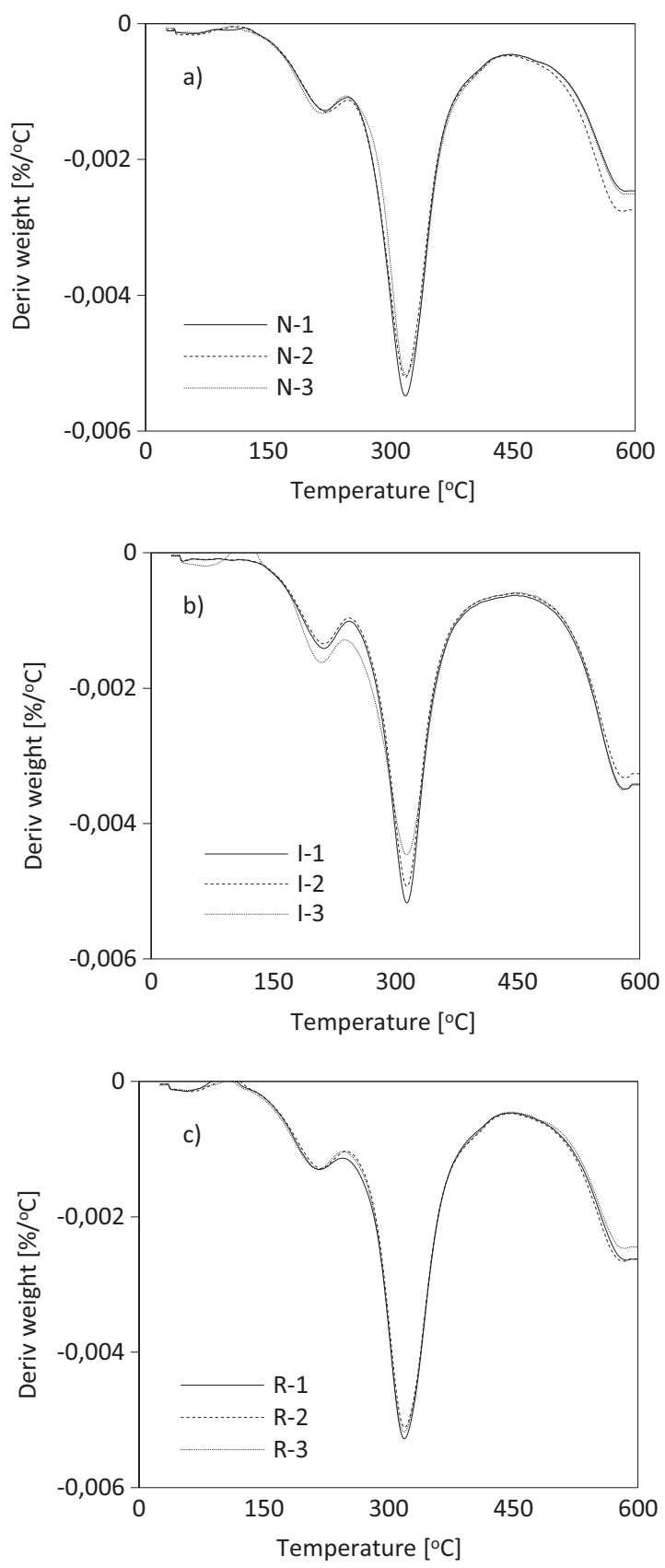

Fig. 21 DTG curves plotted for PUR-PIR aerogels

around $265^{\circ} \mathrm{C}$, while for closed-cell foams degradation starts at temperatures between 210 and $250^{\circ} \mathrm{C}$ [48-53].

\section{Conclusion}

The impact of monomer structure, monomer concentration and solvent type on thermal and mechanical properties of PUR-PIR aerogels was examined. It was found that rigid monomers and polyols yielded materials with lower thermal conductivity and higher modulus than their flexible counterparts. The gelation solvent also played a very important role. However, a relationship between solvent and aerogel properties could not be found. A predictive parameter for the optimum thermal conductivity appears to be the product of density and shrinkage. Low density minimizes conductivity through the solid phase. However, if shrinkage is large, it leads to coalescence of the skeletal nanoparticles into large, ribbon-like aggregates. Thermal bridging by these aggregates can overcome the advantages of low density. Therefore, optimal thermal conductivity requires a trade-off between density and shrinkage.

Funding This study was funded by the Department of Energy (grant number 5120927FF).

\section{Compliance with ethical standards}

Conflict of interest The authors declare that they have no conflict of interest.

Publisher's note Springer Nature remains neutral with regard to jurisdictional claims in published maps and institutional affiliations.

Open Access This article is distributed under the terms of the Creative Commons Attribution 4.0 International License (http://crea tivecommons.org/licenses/by/4.0/), which permits unrestricted use, distribution, and reproduction in any medium, provided you give appropriate credit to the original author(s) and the source, provide a link to the Creative Commons license, and indicate if changes were made.

\section{References}

1. Maleki H (2016) Recent advances in aerogels for environmental remediation applications: a review. Chem Eng J 300:98-118. https://doi.org/10.1016/j.cej.2016.04.098

2. Biesman GL, Randall D, Isterdael E Van (1996) Organic aerogels. PCT/EP96/01782

3. Biesmans G, Randall D, Francais E, Perrut M (1998) Organic gels polyurethane-based organic aerogels' thermal performance. J Non Cryst Solids 225:36-40

4. Biesmans G, Mertens A, Duffours L et al. (1998) Polyurethane based organic aerogels and their transformation into carbon aerogels. J Non Cryst Solids 225:64-68. https://doi.org/10.1016/ S0022-3093(98)00010-6

5. Pirard R, Rigacci A, Maréchal JC et al. (2003) Characterization of hyperporous polyurethane-based gels by non-intrusive mercury porosimetry. Polymer 44:4881-4887. https://doi.org/10.1016/ S0032-3861(03)00481-6

6. Rigacci A, Marechal JC, Repoux M et al. (2004) Preparation of polyurethane-based aerogels and xerogels for thermal superinsulation. J Non Cryst Solids 350:372-378. https://doi.org/10. 1016/J.JNONCRYSOL.2004.06.049

7. Chidambareswarapattar C, McCarver PM, Luo H et al. (2013) Fractal multiscale nanoporous polyurethanes: flexible to extremely rigid aerogels from multifunctional small molecules. Chem Mater 25:3205-3224. https://doi.org/10.1021/cm401623h 
8. Zhu Z, Snellings GMBF, Koebel MM, Malfait WJ (2017) Superinsulating polyisocyanate based aerogels: a targeted search for the optimum solvent system. ACS Appl Mater Interfaces 9:18222-18230. https://doi.org/10.1021/acsami.7b03344

9. Weigold L, Mohite DP, Mahadik-Khanolkar S et al. (2013) Correlation of microstructure and thermal conductivity in nanoporous solids: the case of polyurea aerogels synthesized from an aliphatic tri-isocyanate and water. J Non Cryst Solids 368:105-111. https://doi.org/10.1016/j.jnoncrysol.2013.02.029

10. Abbate FW, Ulrich H (1969) Urethanes. I. Organometallic catalysis of the reaction of alcohols with isocyanates. J Appl Polym Sci 13:1929-1936. https://doi.org/10.1002/app.1969.070130912

11. Smith HA (1963) Catalysis of the formation of urethanes. J Appl Polym Sci 7:85-95. https://doi.org/10.1002/app.1963.070070108

12. Saunders JH, Frisch KC (1962) Polyurethane chemistry and technology I. Chemistry. AmerInterscience Publishers, New York, NY

13. Decostanzi M, Auvergne R, Darroman E et al. (2017) Reactivity and kinetics of HDI-iminooxadiazinedione: application to polyurethane synthesis. Eur Polym J 96:443-451. https://doi.org/10. 1016/j.eurpolymj.2017.09.032

14. Lesar M, Žigon M, Malavašič T (1995) Study of the reaction between 1,5-naphtalene diisocyanate and polycaprolactone in different solvents. J Polym Sci Part A Polym Chem 33:1573-1580. https://doi.org/10.1002/pola.1995.080331003

15. Majoros LI, Dekeyser B, Hoogenboom R et al. (2010) Kinetic study of the polymerization of aromatic polyurethane prepolymers by high-throughput experimentation. J Polym Sci Part A Polym Chem 48:570-580. https://doi.org/10.1002/pola.23768

16. Ni H, Nash HA, Worden JG, Soucek MD (2002) Effect of catalysts on the reaction of an aliphatic isocyanate and water. J Polym Sci Part A Polym Chem 40:1677-1688. https://doi.org/10.1002/pola.10245

17. Han Q, Urban MW (2002) Kinetics and mechanisms of catalyzed and noncatalyzed reactions of $\mathrm{OH}$ and $\mathrm{NCO}$ in acrylic Polyol-1,6hexamethylene diisocyanate (HDI) polyurethanes. VI. J Appl Polym Sci 86:2322-2329. https://doi.org/10.1002/app.11251

18. Monaghan S, Pethrick RA (2012) Solvent effects in polyurethane cure: a model study. Macromolecules 45:3928-3938. https://doi. org/10.1021/ma300514e

19. Kothandaraman H, Nasar AS (1993) The kinetics of the polymerization reaction of toluene diisocyanate with HTPB prepolymer. J Appl Polym Sci 50:1611-1617. https://doi.org/10. 1002/app.1993.070500915

20. Frisch KC, Reegen SL, Floutz WV, Oliver JP (1967) Complex formation between catalysts, alcohols, and isocyanates in the preparation of urethanes. J Polym Sci Part A 5:35-42. https://doi. org/10.1002/pol.1967.150050104

21. Lipatova TE, Bakalo LA, Sirotinskaya AL, Lopatina VS (1970) Mechanism of polyurethane formation with tin dibutyl-laurate. Polym Sci USSR 12:1036-1042. https://doi.org/10.1016/00323950(70)90401-6

22. Leventis N, Sotiriou-Leventis C, Chandrasekaran N et al. (2010) Multifunctional polyurea aerogels from isocyanates and water. A structure-property case study. Chem Mater 22:6692-6710. https:// doi.org/10.1021/cm102891d

23. Taghvaee T, Donthula S, Rewatkar PM et al (2019) K-Index: a descriptor, predictor, and correlator of complex nanomorphology to other material properties. ACS Nano Acsnano. 9b00396. https://doi.org/10.1021/acsnano.9b00396

24. Malakooti S, Rostami S, Churu HG et al. (2018) Scalable, hydrophobic and highly-stretchable poly(isocyanurate-urethane) aerogels. RSC Adv 8:21214-21223. https://doi.org/10.1039/c8ra 03085e

25. Borsus J, Jerome R, Teyssie P (1981) Catalysis of the reaction between isocyanates and protonic substrates. I. Metal salt-amine complexes as catalysts in the polyurea foaming process. J Appl
Polym Sci 26:3027-3043. https://doi.org/10.1002/app.1981. 070260918

26. Farkas A, Mills G (1962) Catalytic effects in isocyanate reactions. Adv Catal 13:393-446. https://doi.org/10.1016/S0360-0564(08) 60290-4

27. Meador MAB, Malow EJ, Silva R et al. (2012) Mechanically strong, flexible polyimide aerogels cross-linked with aromatic triamine. ACS Appl Mater Interfaces 4:536-544. https://doi.org/ 10.1021/am2014635

28. Guo H, Meador MAB, McCorkle L et al. (2012) Tailoring properties of cross-linked polyimide aerogels for better moisture resistance, flexibility, and strength. ACS Appl Mater Interfaces 4:5422-5429. https://doi.org/10.1021/am301347a

29. Xu AR, Wang JJ, Guo X (2017) Fabrication of cellulose aerogels using a green/clean procedure. J Macromol Sci Part B Phys 2348:1-7. https://doi.org/10.1080/00222348.2017.1396825

30. Chidambareswarapattar C, Xu L, Sotiriou-Leventis C, Leventis N (2013) Robust monolithic multiscale nanoporous polyimides and conversion to isomorphic carbons. RSC Adv 3:26459. https://doi. org/10.1039/c3ra43717e

31. Matsumura S, Hlil AR, Lepiller C et al. (2008) Ionomers for proton exchange membrane fuel cells with sulfonic acid groups on the end-groups: Novel branched poly(ether-ketone)s. Am Chem Soc Polym Prepr Div Polym Chem 49:511-512. https://doi.org/ $10.1002 /$ pola

32. Hatchett DW, Kodippili G, Kinyanjui JM et al. (2005) FTIR analysis of thermally processed PU foam. Polym Degrad Stab 87:555-561. https://doi.org/10.1016/j.polymdegradstab.2004.10. 012

33. Chuayjuljit S, Sangpakdee T (2007) Processing and properties of palm oil-based rigid polyurethane foam. J Met Mater Min 17:17-23

34. Hu YH, Gao Y, De Wang N et al. (2002) Rigid polyurethane foam prepared from a rape seed oil based polyol. J Appl Polym Sci 84:591-597. https://doi.org/10.1002/app.10311

35. Stirna U, Beverte I, Yakushin V, Cabulis U (2011) Mechanical properties of rigid polyurethane foams at room and cryogenic temperatures. J Cell Plast 47:337-355. https://doi.org/10.1177/ 0021955X11398381

36. Yang J, Li S, Yan L et al. (2010) Compressive behaviors and morphological changes of resorcinol-formaldehyde aerogel at high strain rates. Microporous Mesoporous Mater 133:134-140. https:// doi.org/10.1016/j.micromeso.2010.04.025

37. Leventis N, Chidambareswarapattar C, Mohite DP et al. (2011) Multifunctional porous aramids (aerogels) by efficient reaction of carboxylic acids and isocyanates. J Mater Chem 21:11981. https:// doi.org/10.1039/c1jm11472g

38. Chidambareswarapattar C, Larimore Z, Sotiriou-Leventis C et al. (2010) One-step room-temperature synthesis of fibrous polyimide aerogels from anhydrides and isocyanates and conversion to isomorphic carbons. J Mater Chem 20:9666. https://doi.org/10.1039/ c0jm01844a

39. Leventis N, Sotiriou-Leventis C, Mohite DP et al. (2011) Polyimide aerogels by ring-opening metathesis polymerization (ROMP). Chem Mater 23:2250-2261. https://doi.org/10.1021/cm200323e

40. Diascorn N, Calas S, Sallee H et al. (2015) Polyurethane aerogels synthesis for thermal insulation-textural, thermal and mechanical properties. J Supercrit Fluids 106:76-84

41. Bang A, Buback C, Sotiriou-Leventis C, Leventis N (2014) Flexible aerogels from hyperbranched polyurethanes: Probing the role of molecular rigidity with poly(Urethane Acrylates) versus poly(Urethane Norbornenes). Chem Mater 26:6979-6993. https:// doi.org/10.1021/cm5031443

42. Lomba Huguet M, Garduno Pèrez J, Torres Cano E et al. (2017) Organic aerogels based on isocyanate and cyclic ether polymer networks, EP3124516A1. 1:1-18 
43. Wu L, Gemert JV, Camargo RE (2008) Rheology study in polyurethane rigid foams. Huntsman Corporation, Auburn Hills, USA

44. Jiao L, Xiao H, Wang Q, Sun J (2013) Thermal degradation characteristics of rigid polyurethane foam and the volatile products analysis with TG-FTIR-MS. Polym Degrad Stab 98:2687-2696. https://doi.org/10.1016/j.polymdegradstab.2013.09.032

45. Levchik SV, Weil ED (2004) Thermal decomposition, combustion and fire-retardancy of polyurethanes-A review of the recent literature. Polym Int 53:1585-1610. https://doi.org/10.1002/pi.1314

46. Septevani AA, Evans DAC, Chaleat C et al. (2015) A systematic study substituting polyether polyol with palm kernel oil based polyester polyol in rigid polyurethane foam. Ind Crops Prod 66:16-26. https://doi.org/10.1016/j.indcrop.2014.11.053

47. Chattopadhyay DK, Webster DC (2009) Thermal stability and flame retardancy of polyurethanes. Prog Polym Sci 34:1068-1133. https://doi.org/10.1016/j.progpolymsci.2009.06.002

48. Członka S, Strakowska A, Strzelec K et al. (2019) Composites of rigid polyurethane foams reinforced with POSS. Polymer 11:1-19. https://doi.org/10.3390/polym11020336
49. Członka S, Bertino MF, Strzelec K (2018) Rigid polyurethane foams reinforced with industrial potato protein. Polym Test 68 . https://doi.org/10.1016/j.polymertesting.2018.04.006

50. Członka S, Sienkiewicz N, Strąkowska A, Strzelec K (2018) Keratin feathers as a filler for rigid polyurethane foams on the basis of soybean oil polyol. Polym Test 72:32-45. https://doi.org/ 10.1016/j.polymertesting.2018.09.032

51. Zieleniewska M, Leszczyński MK, Kurańska M et al. (2015) Preparation and characterisation of rigid polyurethane foams using a rapeseed oil-based polyol. Ind Crops Prod 74:887-897. https:// doi.org/10.1016/j.indcrop.2015.05.081

52. Prociak A, Kurańska M, Cabulis U et al. (2018) Effect of biopolyols with different chemical structures on foaming of polyurethane systems and foam properties. Ind Crops Prod 120:262-270. https://doi.org/10.1016/J.INDCROP.2018.04.046

53. Kuranska M, Prociak A (2012) Porous polyurethane composites with natural fibres. Compos Sci Technol 72:299-304. https://doi. org/10.1016/j.compscitech.2011.11.016 